\title{
Application of a Dynamic Clustered Bayesian Model Averaging (DCBA) Algorithm for Merging Multisatellite Precipitation Products over Pakistan
}

\author{
Khalil Ur Rahman, Songhao Shang, Muhammad Shahid, and Yeqiang Wen \\ State Key Laboratory of Hydroscience and Engineering, Department of Hydraulic Engineering, \\ Tsinghua University, Beijing, China \\ ZEESHAN KHAN \\ School of Economics and Management, Tsinghua University, Beijing, China
}

(Manuscript received 15 April 2019, in final form 4 November 2019)

\begin{abstract}
Merged multisatellite precipitation datasets (MMPDs) combine the advantages of individual satellite precipitation products (SPPs), have a tendency to reduce uncertainties, and provide higher potentials to hydrological applications. This study applied a dynamic clustered Bayesian model averaging (DCBA) algorithm to merge four SPPs across Pakistan. The DCBA algorithm produced dynamic weights to different SPPs varying both spatially and temporally to accommodate the spatiotemporal differences of SPP performances. The MMPD is developed at daily temporal scale from 2000 to 2015 with spatial resolution of $0.25^{\circ}$ using extensively evaluated SPPs and a global atmospheric reanalysis-precipitation dataset: Tropical Rainfall Measurement Mission (TRMM) Multisatellite Precipitation Analysis (TMPA) 3B42V7, Precipitation Estimation from Remotely Sensed Information Using Artificial Neural Networks-Climate Data Record (PERSIANN-CDR), Climate Prediction Center morphing technique (CMORPH), and ERA-Interim. The DCBA algorithm is evaluated across four distinct climate regions of Pakistan over 102 ground precipitation gauges (GPGs). DCBA forecasting outperformed all four SPPs with average Theil's $U$ of $0.49,0.38,0.37$, and 0.36 in glacial, humid, arid, and hyperarid regions, respectively. The average mean bias error (MBE), mean error (MAE), root-mean-square error (RMSE), correlation coefficient (CC), and standard deviation (SD) of DCBA over all of Pakistan are $0.54,1.40,4.94,0.77$, and $5.17 \mathrm{~mm} \mathrm{day}^{-1}$, respectively. Seasonal evaluation revealed a dependency of DCBA performance on precipitation magnitude/intensity and elevation. Relatively poor DCBA performance is observed in premonsoon/monsoon seasons and at high/mild elevated regions. Average improvements of DCBA in comparison with TMPA are 59.56\% (MBE), 49.37\% (MAE), 45.89\% (RMSE), $19.48 \%$ (CC), $46.7 \%$ (SD), and $18.66 \%$ (Theil's $U$ ). Furthermore, DCBA efficiently captured extreme precipitation trends (premonsoon/monsoon seasons).
\end{abstract}

\section{Introduction}

Precipitation is a fundamental element of hydrological and climate studies. Precise estimation of high-quality precipitation, including the magnitude, intensity, and spatiotemporal variation, are essential to amend our understanding of hydrological and meteorological cycles from regional to global scales (Ma et al. 2018b). The hydrological processes are significantly impacted by spatial and temporal changes in precipitation (Kidd and Huffman 2011; Sorooshian et al. 2011). The spatiotemporal variation of precipitation expressively contributes to socioeconomic

Corresponding author: Songhao Shang, shangsh@tsinghua.edu.cn factors, including food security, ecosystem health, disaster management, and hydropower generation (Tong et al. 2014). Therefore, precise estimation of precipitation with sufficient spatiotemporal resolution is necessary for hydrological modeling and simulations (Miao et al. 2015; M. Yu et al. 2011), which is a challenging task due to its spatiotemporal variability (Fang et al. 2013), particularly in ungauged or poorly gauged watersheds (Moazami et al. 2016).

The gauge-based observation and radar networks are considered as traditional in situ precipitation data sources. However, both of these networks are sparsely distributed and not sufficient to capture the spatial and temporal variation in precipitation (Miao et al. 2015; Yong et al. 2011). There are numerous errors associated 
with the distribution and readings of these in situ precipitation data sources (Tapiador et al. 2017). To surmount these uncertainties, utilization of satellite-based precipitation products (SPPs) from regional- to globalscale precipitation estimation has significantly increased over the past 30 years (Sun et al. 2016; Tang et al. 2016). The development of high-resolution precipitation datasets has provided unprecedented opportunities for monitoring the spatiotemporal variability in precipitation on a global scale, more specifically at high-elevation regions with limited or scarce ground-based observations (Huffman et al. 2007; Mahmoud et al. 2018).

Various studies have evaluated different SPPs against the ground-based precipitation gauges (GPGs) on regional and global scales, which are discussed in detail by Rahman et al. (2018). The comprehensive evaluation of previously conducted studies provided that on the basis of mean error, correlation with the GPGs and other categorical indices (false alarm ratio, probability of detection, and critical success index), the successors SPPs performances are significantly better than the predecessors. Contrarily, in the complex terrain and region with highly rapid precipitation gradients, most of the SPPs showed a weaker correlation with GPGs and high associated mean errors. Besides the topography, climate and seasonality of a region also play a critical role in the performance of SPPs. Significantly better performance has been observed in the semiarid regions as compared to the equatorial and tropical regions (Ringard et al. 2015).

Among the different SPPs evaluated in Pakistan, Tropical Rainfall Measuring Mission (TRMM) performance is better over plains and medium-elevation regions. TRMM overestimated precipitation in the north of Pakistan (glacial and humid regions), and consistent performance is observed in the arid and hyperarid regions. The performance of the SPPs shows greater topographic dependency and also dependent on the variability of many factors, including climate variability, temporal variation (daily, monthly, seasonal, and annually) and precipitation intensities (Maggioni et al. 2016). However, the SPPs performances are getting better and better day by day, but there is still room for further improvement in performance of the SPPs.

Several efforts, for example, improvement in calibration algorithms, reducing sampling issues, using relative weights, weight estimation using the dynamic methods, merging more than two different satellite products, and so forth, have been made to avoid such kind of nonnegligible errors in SPPs (Ma et al. 2018a; Rahman et al. 2018; Tang et al. 2016). The accuracy of meteorological and hydrological models application could be significantly improved using the merging approaches based on different statistical models or even the different members of the same statistical model (Raftery et al. 2005). Simple merging using the model averaging synthesizes single information from multiple members, and the performance is better than all or most of the individual members. Rahman et al. (2018) used the principal component analysis (PCA) and sample $t$-test comparison method to merge two SPPs including GPM-IMERG and TRMM Multisatellite Precipitation Analysis (TMPA) 3B43v7. The results demonstrated that the merged product outperformed all the SPPs (except GPM-IMERG at few gauge locations) in different climate regions of Pakistan. Simple model averaging (SMA) approach performed significantly better than all individual SPPs for estimating the climate and hydrological variables (Duan and Phillips 2010; Raftery et al. 2005; Wu et al. 2012). Shen et al. (2014) evaluated the one outlier removed (OOR) method and reported better performance of OOR than SMA in precipitation estimation for all the seasons except the winter across the Tibetan Plateau.

The key objectives of the current study are to present a merged multisatellite precipitation product (MMPD) using dynamic clustered Bayesian model averaging (DCBA) over Pakistan and to evaluate its performance on regional and seasonal scales. This experiment is performed using four comprehensively evaluated SPPs in Pakistan, including the TRMM TMPA 3B42v7, Climate Prediction Center morphing technique (CMORPH), ERA-Interim, and Precipitation Estimation from Remotely Sensed Information Using Artificial Neural Networks-Climate Data Record (PERSIANN-CDR) (Hong et al. 2004), at the daily scale for 16 years (2000-15). This study is organized as follows: section 2 introduces the study area, datasets, and methods, sections 3 and 4 represent the comprehensive evaluation and discussion, and section 5 is the conclusion of the current research.

\section{Study area, datasets, and method}

\section{a. Study area}

This study has been conducted over Pakistan, situated between $23.5^{\circ}$ and $37.5^{\circ} \mathrm{N}$ latitude and between $62^{\circ}$ and $75^{\circ} \mathrm{E}$ longitude with an area of $803940 \mathrm{~km}^{2}$ (Fig. 1a). The study area is bounded by China at its north, India on the east, Iran and Afghanistan on the west, and the Arabian Sea at the south. Pakistan has diverse and complex topography with elevation ranging from $0 \mathrm{~m}$ (Arabian Sea) to $8600 \mathrm{~m}$ (Himalaya and Karakoram Mountain ranges). Pakistan has a diverse 
(a)

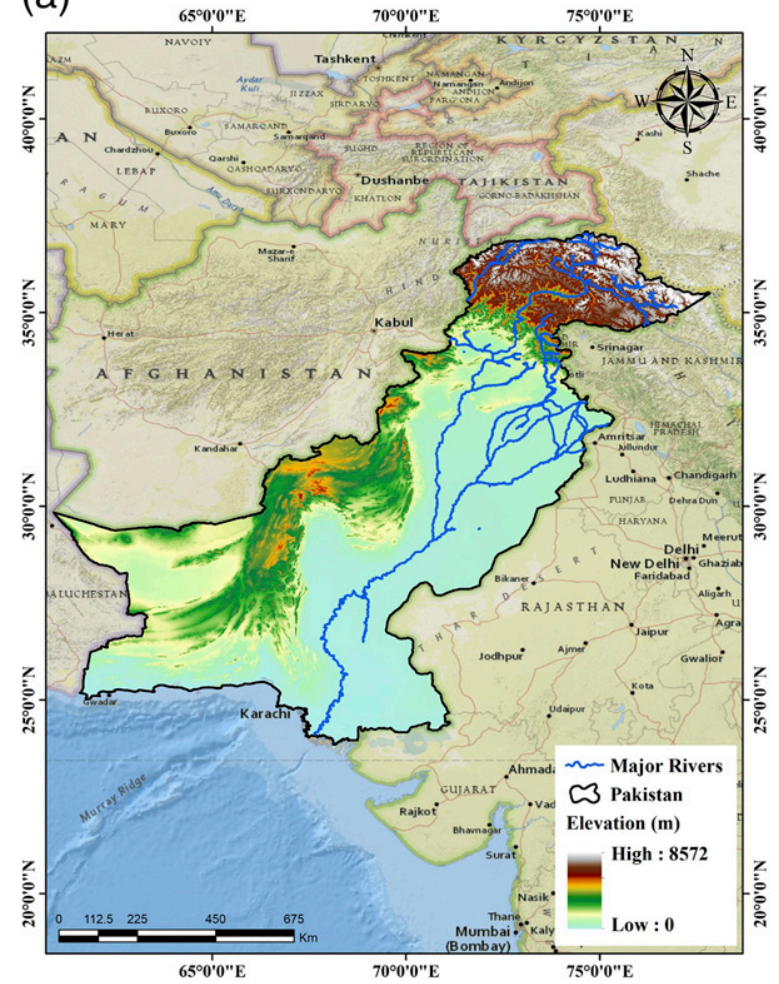

(b)

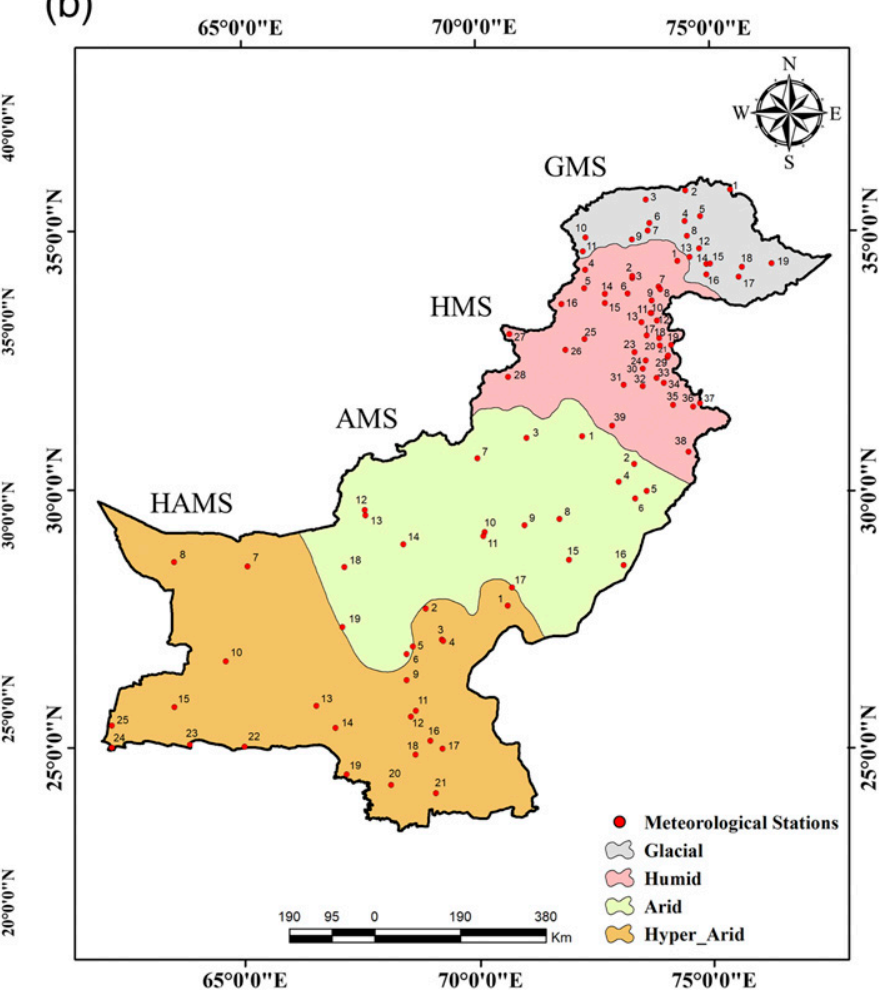

FIG. 1. Study area and the location of GPGs. (a) Elevation of Pakistan derived from the Shuttle Radar Topography Model (SRTM) and (b) division of four climate regions considered in this study. Numbers in (b) represent the number of GPGs in glacial (GMS), humid (HMS), arid (AMS), and hyperarid (HAMS) climate regions, respectively.

climate, which changes abruptly from glacial region to the hyperarid region and accordingly, the study area is divided into four major climate regions, which are glacial, humid, arid, and hyperarid regions. The glacial region is located at the extreme north part of the country, and its mean elevation is about $4158 \mathrm{~m}$. This region is mostly covered by snow and glaciers. The famous mountains of the Hindu Kush Himalayas are also located in this region, which are known as one of the most famous snow mountains after the polar region. Snow and glaciers from these mountains melt in summer and feed the Indus River, which is the primary source of domestic, industrial, and agricultural water use in Pakistan. Moreover, the excessive melting of snow and glaciers has also caused acute flooding in the country, and the 2010 flood is one of these disastrous floods, which severely damaged the country's economy and took thousands of lives. The humid region consists of very high mountains of the Karakorum, Hindu Kush, and Himalaya regions and almost all major rivers of the country (Indus, Kabul, Swat, Panjkora, Gilgit, Chitral, Hunza, Kurram, and Jhelum) originate from these mountains. Mean elevation and mean annual precipitation of the humid region is $1286 \mathrm{~m}$ and $852 \mathrm{~mm} \mathrm{yr}^{-1}$, respectively. The arid region mostly consists of the major agricultural regions of Punjab Province. The Indus River and its tributaries drain in this region and are considered as the primary source of water for this region. The average elevation of the arid region is $663 \mathrm{~m}$ with mean annual precipitation of $322 \mathrm{~mm} \mathrm{yr}^{-1}$. The hyperarid region includes the Sindh and Balochistan Provinces and the south part of Punjab Province. Most of the hyperarid region consists of barren lands and dry mountain ranges. The mean elevation of the hyperarid region is $444 \mathrm{~m}$, and a very low mean annual precipitation of $133 \mathrm{~mm} \mathrm{yr}^{-1}$ is recorded across this region.

\section{b. Rain gauge precipitation data}

GPGs provide the direct precipitation measurement records and are considered as a standard precipitation measurement source for SPPs calibration and validation processes. The meteorological data of Pakistan are owned by two organizations, the Pakistan Meteorology Department (PMD) and the Snow and Ice Hydrology Project (SIHP) of Water and Power Development Authority (WAPDA). The daily GPG records (mm day ${ }^{-1}$ ) of 102 meteorological stations from 2000 to 2015 
have been collected from both organizations. Out of 102 meteorological stations, precipitation records of 23 GPGs are collected from WAPDA and 79 GPGs from PMD. The locations and distribution of meteorological stations are shown in Fig. 1b. The SIHP operates the meteorological stations at high elevations of the country and are mostly situated in the glacial and humid regions. In the current study, the meteorological stations are named with respect to each region, that is, the stations in the glacial, humid, arid, and hyperarid regions are represented as GMS, HMS, AMS, and HAMS, respectively. The main features of selected climate regions are listed in Table 1.

PMD and WAPDA manually collect most of the GPG records, which might be subjected to personal and instrumental errors. Furthermore, the stations located at high elevations may also be subjected to other errors such as splashing and wind errors, which can affect the quality of the data. Therefore, the evaluation and corrections of the GPG records are performed by PMD and WAPDA following the World Meteorological Organization standard code (WMO-N). Moreover, the data quality tests such as skewness and kurtosis methods are performed on the collected GPG data, and the missing data are filled using the zero-order method (Rahman et al. 2018).

\section{c. Satellite precipitation datasets}

Three satellite-based precipitation datasets (TMPA 3B42-v7, PERSIANN-CDR, and CMORPH) and one reanalysis precipitation dataset (ERA-Interim) are optically merged using the DCBA algorithm. The selection of datasets mentioned above is based on their comprehensive evaluation in the past over the study area (Pakistan).

\section{1) TMPA $3 B 42-v 7$}

TRMM mission is a joint effort of the United States National Aeronautics and Space Administration (NASA) and the Japan Aerospace Exploration Agency (JAXA). The TMPA algorithm produces two main precipitation products, which are known as 3B42-RT and 3B42-v6/3B42-v7. The 3B42-RT is also known as the real-time version, and the other two are known as the post-real-time research-grade products. The real-time and post-real-time research-grade product algorithms have procedural similarities. However, 3B42-V7 uses the global real-time precipitation datasets from the Global Precipitation Climatology Centre (GPCC) to enhance the calibration process. Currently, TMPA is producing the best precipitation estimates at $0.25^{\circ}$ spatial resolution for the areas between $50^{\circ} \mathrm{S}$ and $50^{\circ} \mathrm{N}$.
TABLE 1. Main features of the four climate regions.

\begin{tabular}{lrccc}
\hline \hline Region & $\begin{array}{c}\text { Area } \\
\left(\mathrm{km}^{2}\right)\end{array}$ & $\begin{array}{c}\text { Average } \\
\text { elevation }(\mathrm{m})\end{array}$ & $\begin{array}{c}\text { Average annual } \\
\text { precipitation }(\mathrm{mm})\end{array}$ & $\begin{array}{c}\text { No. of } \\
\text { stations }\end{array}$ \\
\hline Glacial & 72774 & 4158 & 348 & 19 \\
Humid & 137753 & 1286 & 852 & 39 \\
Arid & 270484 & 633 & 322 & 19 \\
Hyperarid & 322929 & 444 & 133 & 25 \\
\hline
\end{tabular}

The TMPA 3B42-v7 has many advanced specifications as compared to the previous versions, including additional satellite inputs, a newer infrared (IR) brightness temperature dataset, a latitude band calibration system for all satellites, uniform data from current algorithms, and a single uniformly processed surface precipitation analysis (Huffman et al. 2007). TMPA 3B42-v7 (denoted as TMPA onward) is used in this study.

\section{2) PERSIANN-CDR}

The PERSIANN algorithm is developed by the Center of Hydrometeorology and Remote Sensing (CHRS) at the University of California, Irvine. The spatial resolution of PERSIANN is $0.25^{\circ} \times 0.25^{\circ}$ with daily temporal resolution (Ashouri et al. 2015). PERSIANN uses passive microwave (PMW) data (TMI, AMSU-B, and SSM/I) to adjust the neural network parameters for enhancing the accuracy of precipitation estimation. The PERSIANNCDR product from the PERSIANN family is developed by CHRS having the same spatial resolution. The PERSIANN-CDR uses the same neural network for precipitation estimation as used by the previous products. The only difference in the algorithm is the input IR dataset with the use of Gridded Satellite (GridSat)-B1 instead of Climate Prediction Center (CPC)-IR. Moreover, the PMW data are not used in PERSIANN-CDR (Ashouri et al. 2015).

\section{3) $\mathrm{CMORPH}$}

The CMORPH precipitation dataset is developed by the CPC. CMORPH utilizes IR-based motion vectors to propagate the high-quality precipitation derived from the PMW data (Joyce et al. 2004). The IR data used in the CMORPH's algorithm integrate the observations from Geostationary Operational Environmental Satellite- 8 (GOES-8) and GOES-10, Meteosat-5 and Meteosat-8, and Geostationary Meteorological Satellite-5 (GMS-5) satellites. National Oceanic and Atmospheric Administration (NOAA) polar-orbiting operational meteorological satellites, the Defense Meteorological Satellite Program (DMSP) satellites, and TRMM are used in the PMWderived precipitation estimation in CMORPH. The data of CMORPH are available at 3-h temporal resolution with a spatial resolution of $0.25^{\circ}$. 


\section{4) REANALYSIS PRECIPITATION PRODUCT}

ERA-Interim, a global atmospheric reanalysis precipitation dataset developed by ECMWF (European Centre for Medium-Range Weather Forecasts), is used as a final precipitation product in the current study. ERA-Interim provides real-time global precipitation records from 1979 to present with a spatial resolution of $80 \mathrm{~km}$ on 60 vertical levels from the surface up to $0.1 \mathrm{hPa}$. The ERA-Interim data are produced from the data assimilation system based on the 2006 release of the Integrated Forecasting System (IFS Cy31r2). It includes a four-dimensional variational (4D-Var) analysis having 12-h window. ERA-Interim uses the weather forecast model to estimate the precipitation based on temperature and relative humidity (Dee et al. 2011). Improvements in ERA-Interim are made by revising the methods for bias correction in radiance data and the humidity analysis. The improved version of ERA-Interim has advantages on high altitude region by providing better depictions than the Global Precipitation Climatology Project (GPCP) (Berrisford et al. 2011).

\section{d. Dynamic clustered Bayesian model averaging algorithm}

The clustered Bayesian model averaging (CBA) accounts for the nonregionality of the Bayesian model averaging (BMA) algorithm in such a way that it still allows us to make substantial use of the Bayes theorem (Yu et al. 2013). CBA combines the merging members (selected four SPPs here) based on Bayesian analysis using adaptive weights. During the CBA analysis, covariate space is divided into different subregions in such a way that the relative performance of merging members is the same in a particular region but differs from other regions (Yu et al. 2013). As a result, weights produced by CBA vary with clustered regions, while being kept constant in time. Studies have shown that the performance of SPPs varies with the season (Ward et al. 2011; Hussain et al. 2018; Iqbal and Athar 2018), and therefore, the weights are varied dynamically in the BMA scheme of merging SPPs (Ma et al. 2018a). Considering the advantages of dynamic BMA (DBMA), we used dynamic CBA (DCBA) to obtain weights of SPPs varying both spatially and temporally.

CBA analyses are carried out in a pixel-by-pixel way, where the pixel of each GPG is carefully checked for spatiotemporal coincidence with SPPs. CBA weights of four merging members are adjusted at each GPG on a daily temporal scale. Then, the CBA weights are applied to the next day's merge. On the basis of the previous day's CBA weights, the next day's weights are calculated using a moving averaging approach. Based on the previous studies, 40 days of a training period for each year is selected (Hamill 2007; Ma et al. 2018a). Ma et al. (2018a) found that increasing training period improves the results, but no significant improvements are observed beyond 40 days. Therefore, one training period of 40 days in the current year and four training periods (40 days each) of the same time from the previous four years (a total of 200 days) are selected to optimize the CBA weights. CBA analyses are performed when more than one SPP captures the "true" precipitation (precipitation captured both by SPPs and GPGs). Precipitation magnitude of $1 \mathrm{~mm}$ is considered as the precipitation/no precipitation threshold (Chen and Li 2016).

The methodology adopted in this study comprised the following major steps. Readers are referred to Yu et al. (2013), for a comprehensive description of the CBA methodology.

1) Clustering, which is the process of partitioning the covariate space (entire study region) $\Lambda$ into a finite number $K$ disjoint regions such that $\Lambda=\Lambda_{1} \cup \Lambda_{2} \cup$ $\Lambda_{3} \cup \ldots \cup \Lambda_{K}$. Clustering is classified into two major categories: unsupervised learning, such as clustering based on $K$ means, $K$ medians, single linkage, complete linkage, and so on, and supervised learning, that is, clustering based on the predefined regions or mean elevation or mean daily/monthly/annual precipitation, and so on. In this study, we performed supervised clustering by dividing the covariate space into glacial, humid, arid, and hyperarid regions $(K=4)$.

2) Calculation of the Bayes factor (BF), which is used to test the Bayesian hypothesis and to compare the performance of Bayesian models (Jeffreys 1961; Kass and Raftery 1995). BFs are preferred to modelselection criteria as they incorporate both prior and posterior distribution information of merging members. This information indicates how good each merging member fits the data compared to the observed data. Jeffreys (1961) proposed the interpretation of BF values based on half-units of log metric (shown in Table 2) against the base information (observed data). Higher BF values indicate the best performance of the merged dataset against the observed data.

3) CBA algorithm: The following regression is considered for CBA analysis

$$
y_{i}=g\left(x_{i}\right)+\varepsilon_{i}, \quad i=1, \ldots, n,
$$

where $n$ is the number of merging members, $\left\{x_{i}\right\}_{i=1}^{n}$ are independently and identically distributed (i.i.d) variables (precipitation data of each merging member) drawn from the joint distribution of $x, g$ is a deterministic function, and $\varepsilon_{I}$ are i.i.d residuals with mean 0 , variance $\sigma^{2}$, and independent of $\left\{x_{i}\right\}_{i=1}^{n}$. 
TABLE 2. Bayes factor (BF), $\log (\mathrm{BF})$ and its relation with the observed data.

\begin{tabular}{lll}
\hline \hline \multicolumn{1}{c}{ BF } & $\log (\mathrm{BF})$ & $\begin{array}{c}\text { Evidence against the } \\
\text { observed data }\end{array}$ \\
\hline 1 to 3.2 & 0 to $1 / 2$ & Bare mention \\
3.2 to 10 & $1 / 2$ to 1 & Substantial \\
10 to 100 & 1 to 2 & Strong \\
$>100$ & $>2$ & Very strong \\
\hline
\end{tabular}

4) Calculation of dynamic merged weights, that is, $\left\{\Delta_{t}\right\}_{t=1}^{T}$ (dependent on time $t=1,2, \ldots, T$, where $T$ represents days of the training period, that is, 40 days for 5 years with a total of 200 days) for four SPPs based on the training dataset $Z=\left\{\left(x_{i}, y_{i}\right)\right\}_{i=1}^{n}$. This step is further divided into the following substeps.

(i) Random permutation of training datasets $Z=$ $\left\{\left(x_{i}, y_{i}\right)\right\}_{i=1}^{n}$ and splitting into two parts $Z_{1}$ and $Z_{2}$.

(ii) Calculation of posterior distribution of each merging member conditional on $Z_{1}$ using the formula

$$
p_{j}\left(M_{j} \mid Z_{1}\right)=\frac{p\left(Z_{1} \mid M_{j}\right) p\left(M_{j}\right)}{\sum p\left(Z_{1} \mid M_{j}\right) p\left(M_{j}\right)},
$$

where $j=1,2$.

(iii) Calculation of marginal likelihood, local $\mathrm{BF}$, and $\log (\mathrm{BF})$ of each observation in the dataset $Z_{2}$.

(iv) Calculation of merged weights of each merging member. The process from step (i) to (iv) is iterated $Q$ times such that $q=\{1,2, \ldots, Q\}$ to get the merging member weights.
5) The following equation is used for final prediction of MMPD

$$
\hat{\Delta}=w_{1 t} \Delta_{1 t}+\left(1-w_{1 t}\right) \times \Delta_{2 t} .
$$

CBA is designed to compare two merging members and calculate $\mathrm{BF}$ for the corresponding two members. However, it has the flexibility to combine more than two individual SPPs by using the geometric mean of the calculated BF (Q. Yu et al. 2011). In the current study, CBA is repeated for two sets of merging members, and then geometric mean is computed to get the final MMPD.

\section{e. Performance evaluation of the models}

DCBA MMPD is evaluated and compared against the GPG observations using several statistical indices, including mean bias error (MBE), mean absolute error (MAE), root-mean-square error (RMSE), correlation coefficient (CC), standard deviation (SD) (Anjum et al. 2016; Ebert 2007), and the Theil's $U$ coefficient (Bliemel 1973). The complete description of statistical indices is presented in Table 3. Positive MBE represents overestimation, while negative values indicate underestimation by MMPD with respect to the GPGs. MAE indicates the average absolute error between the DCBA simulated and GPGs observations, while RMSE estimates error in terms of squared error. RMSE is selected for evaluating the average error magnitude between simulated and observed precipitation data. CC computes the agreement between simulated and observed observations. SD is another useful statistical

TABLE 3. Statistical indices used to evaluate the performance of DCBA MMPD. Here, $M$ is the simulated (merged precipitation) data from each statistical model, $O$ is the observed precipitation data from GPGs, $n$ is the number of samples, $X$ is the data element $(X=M$ for

\begin{tabular}{|c|c|c|}
\hline Statistical index & Equation & Perfect value \\
\hline Mean bias error (MBE) & $\mathrm{MBE}=\frac{1}{n} \sum_{i=1}^{n}\left(M_{i}-O_{i}\right)$ & 0 \\
\hline Mean absolute error (MAE) & MAE $=\frac{1}{n} \sum_{i=1}^{n}\left|M_{i}-O_{i}\right|$ & 0 \\
\hline Root-mean-square error (RMSE) & $\mathrm{RMSE}=\sqrt{\frac{1}{n} \sum_{i=1}^{n}\left(M_{i}-O_{i}\right)^{2}}$ & 0 \\
\hline Correlation coefficient (CC) & $\mathrm{CC}=\frac{\sum_{i=1}^{n}\left(M_{i}-\overline{M_{i}}\right)\left(O_{i}-\overline{O_{i}}\right)}{\sqrt{\sum_{i=1}^{n}\left(M_{i}-\overline{M_{i}}\right)^{2}} \sqrt{\sum_{i=1}^{n}\left(O_{i}-\overline{O_{i}}\right)^{2}}}$ & 1 \\
\hline Standard deviation (SD) & $\mathrm{SD}=\sqrt{\frac{1}{n} \sum_{i=1}^{n}(X-\bar{X})^{2}}$ & - \\
\hline Theil's $U$ & $U=\sqrt{\sum_{i=1}^{n}\left(M_{i}-O_{i}\right)^{2} / \sum_{i=1}^{n} M_{i}^{2}}$ & 0 \\
\hline
\end{tabular}
the DCBA while $X=O$ for GPGs), and bars on the variables represent the average values. 
index to describe the capability of MMPD to capture the precipitation variability. A higher value of SD indicates higher variation in simulated precipitation data from its mean value. Theil's $U$ coefficient is used to evaluate the accuracy of DCBA forecast related to GPGs. Theil's $U$ coefficient can be related to $R^{2}$, but it is not bounded by zero and one. The lower boundary of Theil's $U$ is zero indicating perfect forecasting; it assumes the value of 1 when DCBA forecasts the same error as the naive no-change extrapolation. A value greater than 1 indicates the worst forecasting and has to be rejected (Bliemel 1973). Since only hit cases are considered to develop the MMPD, the categorical indices such as false alarm ratio (FAR), probability of detection (POD), and critical success index (CSI) are not considered to evaluate the performance of MMPD.

\section{Results}

Uncertainties associated with SPPs depend on topography, elevation, seasonality, and time scale (Romilly and Gebremichael 2011), which in turn contribute to the distribution/assignment of weights to each merging member. Precipitation estimates using SPPs give comparatively better results (low uncertainties) on a monthly or larger time scale than a daily time scale (Tong et al. 2014). However, previous studies have reported that MMPDs significantly reduced the uncertainties associated with individual SPPs and showed better performance (Duan and Phillips 2010; Ma et al. 2018a; Rahman et al. 2018; Shen et al. 2014). This section covers the results of spatiotemporal distribution of DCBA weights (section 3a), statistical evaluation of DCBA over four climate regions, that is, glacial, humid, arid, and hyperarid regions (section $3 \mathrm{~b}$ ), seasonal scale evaluation (section 3c), and finally the comparison of developed MMPD performance with the merging members (section $3 \mathrm{~d}$ ).

\section{a. Spatiotemporal distribution of DCBA weights over Pakistan}

Figure 2 shows the spatial distribution of average annual DCBA weights over Pakistan. The analysis reveals that DCBA merged all SPPs in such a way that MMPD has properties of all the merging members. The average weights of each individual SPP are 0.29 (TMPA), 0.27 (PERSIANN-CDR), 0.22 (ERA-Interim), and $0.22(\mathrm{CMORPH})$. On a regional scale, the glacial region is dominated by TMPA (Fig. 2a) and PERSIANNCDR (Fig. 2c) with the relative average weights of 0.34 and 0.26 , respectively. A different trend is observed in the humid region where PERSIANN-CDR shows higher skills (0.32) than TMPA (0.29). Previous studies have confirmed higher skills of TMPA in glacial and mountainous regions of Pakistan as compared to CMORPH and PERSIANN-CDR (Hussain et al. 2018; Rahman et al. 2018). Therefore, in this study, DCBA has assigned higher weights to TMPA, followed by PERSIAN-CDR in glacial and humid regions. However, ERA-Interim replaces PERSIANN-CDR in the arid region and shows higher skills similar to TMPA with an average weight of 0.28 . Moreover, in the hyperarid region, a similar trend as compared to the glacial region is observed, where TMPA (0.28) dominated the PERSIANN-CDR (0.26). Another reason for variation in weights is elevation that affects the SPPs accuracy due to different algorithms (Almazroui 2011; Derin and Yilmaz 2014; Hirpa et al. 2010)

The seasonal (premonsoon, monsoon, postmonsoon, and winter) distribution of relative weights of the four merging members over Pakistan during 2000-15 are shown in Figs. 3-6. The temporal span of the four seasons is premonsoon (April-June), monsoon (JulySeptember), postmonsoon (October and November), and winter (December-March). A higher percentage $(60 \%)$ of precipitation is received during the monsoon season in Pakistan, which varies spatially in magnitude from low $(<100 \mathrm{~mm})$ in the glacial region $\left(34^{\circ}-36^{\circ} \mathrm{N}\right)$, to high $(>700 \mathrm{~mm})$ in the northeast $\left(29^{\circ}-\right.$ $33^{\circ} \mathrm{N}$ ) and to low again (around $100 \mathrm{~mm}$ ) in the south $\left(24^{\circ}-28^{\circ} \mathrm{N}\right)$ (Khan et al. 2014; Rahman et al. 2018). Heavy precipitation is observed in high-elevation regions in northern and central parts of Pakistan, whereas light precipitation occurs in the plains and low-elevation regions of southern and western parts.

The spatial distribution of weights in the premonsoon season (Fig. 3) shows that TMPA dominates other SPPs. Average weights of the merged members over Pakistan are 0.39 (TMPA), 0.25 (ERA-Interim), 0.19 (PERSIANN-CDR), and 0.17 (CMORPH). On the regional scale, TMPA shows the highest performance skills in glacial (0.41) and humid (0.40) regions. However, there is no significant variation in the weights of TMPA in other climate regions, that is, average weights in arid and hyperarid regions are 0.36 and 0.35 . In contrast, ERA-Interim presents the highest performance in hyperarid (0.28) and arid (0.26) regions. Moreover, PERSIANN-CDR and CMORPH show higher skills in hyperarid (0.20) and arid (0.19) regions, respectively.

TMPA and ERA-Interim present higher skills during the monsoon season (Fig. 4) with average weights of 0.31 and 0.27 . Based on the regional analysis, TMPA has the highest average weights in glacial (0.35) and humid (0.32) regions and gradually declines toward the arid $(0.30)$ and hyperarid $(0.28)$ regions. However, a contrasting trend is 
(a)
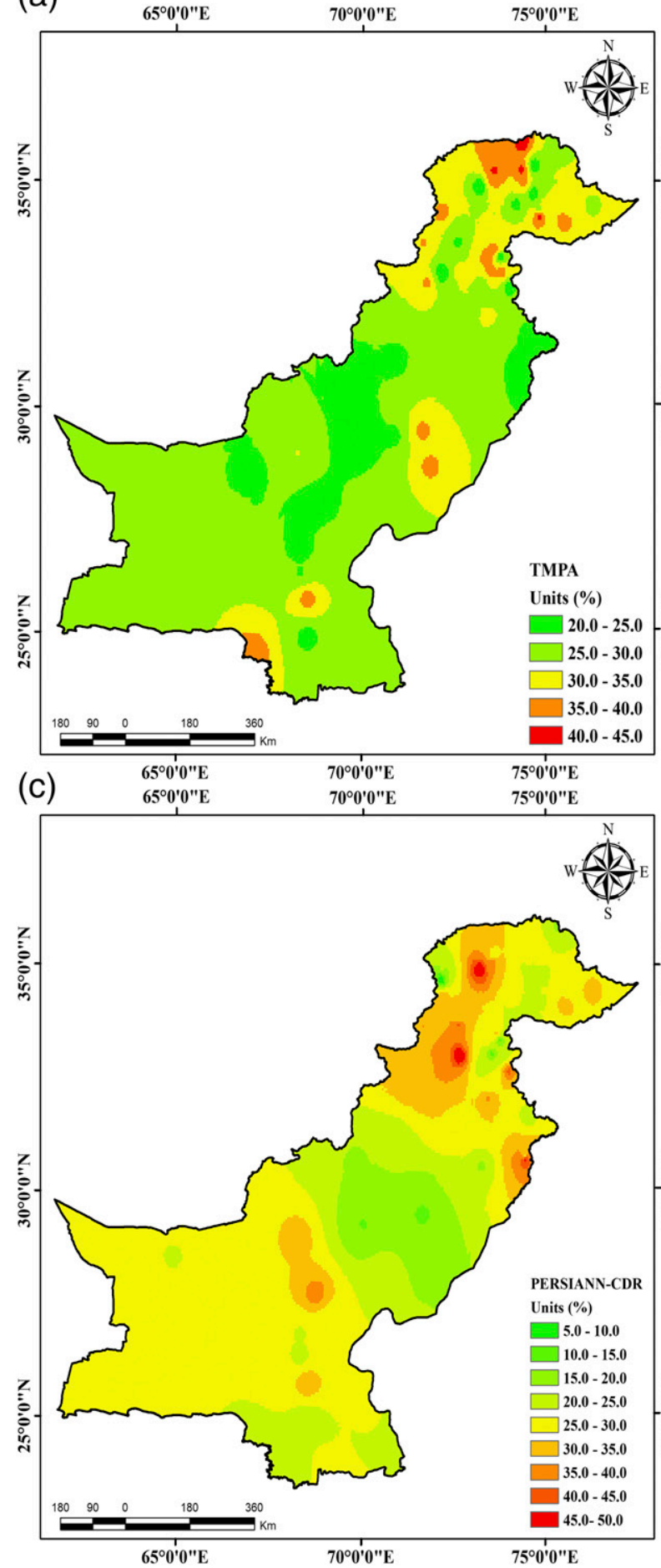

(b)

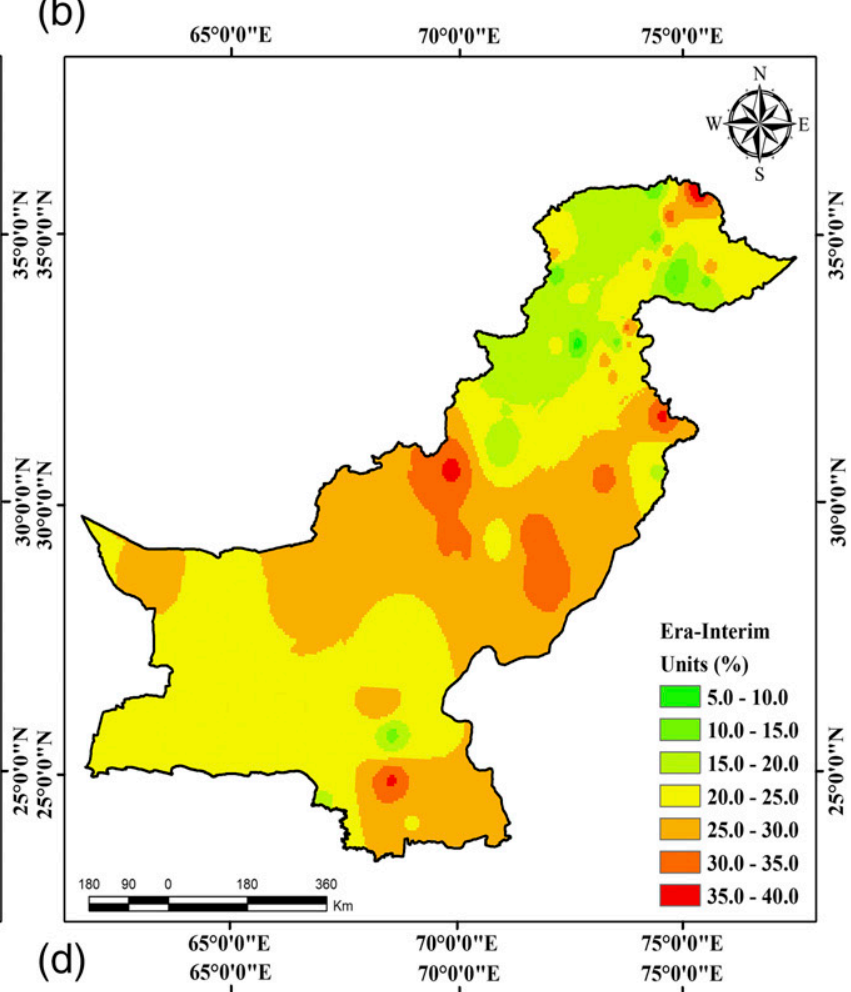

FIG. 2. Spatial distribution of DCBA average weights of the merging members during 2000-15.

observed for ERA-Interim showing higher skills in hyperarid (0.30) and arid (0.29) regions followed by humid (0.25) and glacial (0.22) regions. The average weights for PERSIANN-CDR over all the climate regions range from 0.21 (arid region) to 0.27 (hyperarid region). Similarly, the average weights of CMORPH range from a minimum of 0.15 (hyperarid region) to a maximum 0.20 (arid region). TMPA, PERSIANN-CDR, and CMORPH 


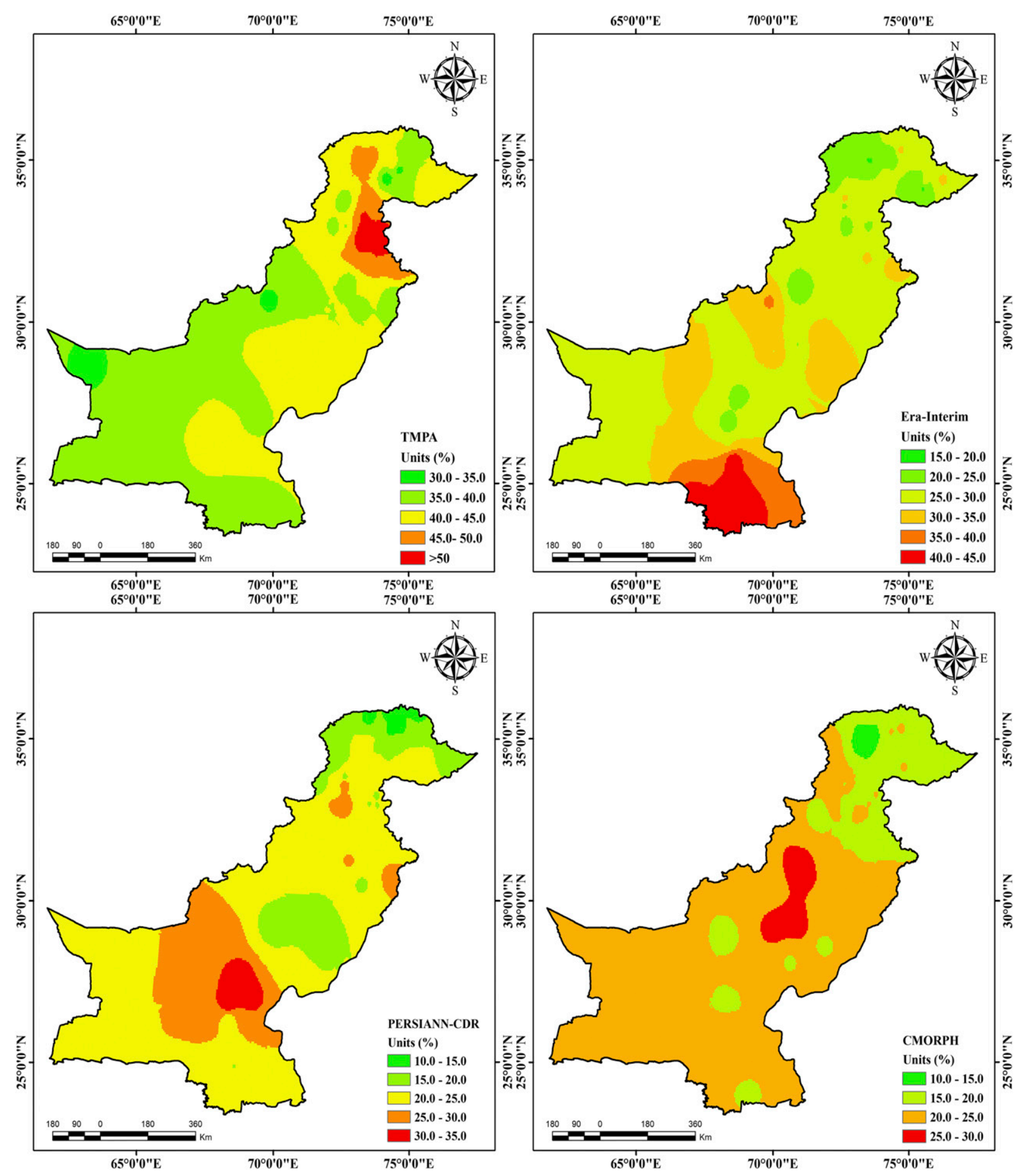

FIG. 3. Spatial distribution of relative DCBA weights of merging members in the premonsoon season during 2000-15.

overestimate intense precipitation in premonsoon and monsoon seasons (Behrangi et al. 2011; Rahman et al. 2018). However, TMPA has the capability to detect moderate to heavy precipitation events across Pakistan (Hussain et al. 2018). CMORPH considerably overestimate moderate precipitation ( $\mathrm{Li}$ et al. 2014). Therefore, during premonsoon and monsoon seasons, DCBA assigned higher weights to TMPA [which supports the findings of Iqbal and Athar (2018) and Rahman et al. (2018)] and ERA-Interim (replacing PERSIANN-CDR). 


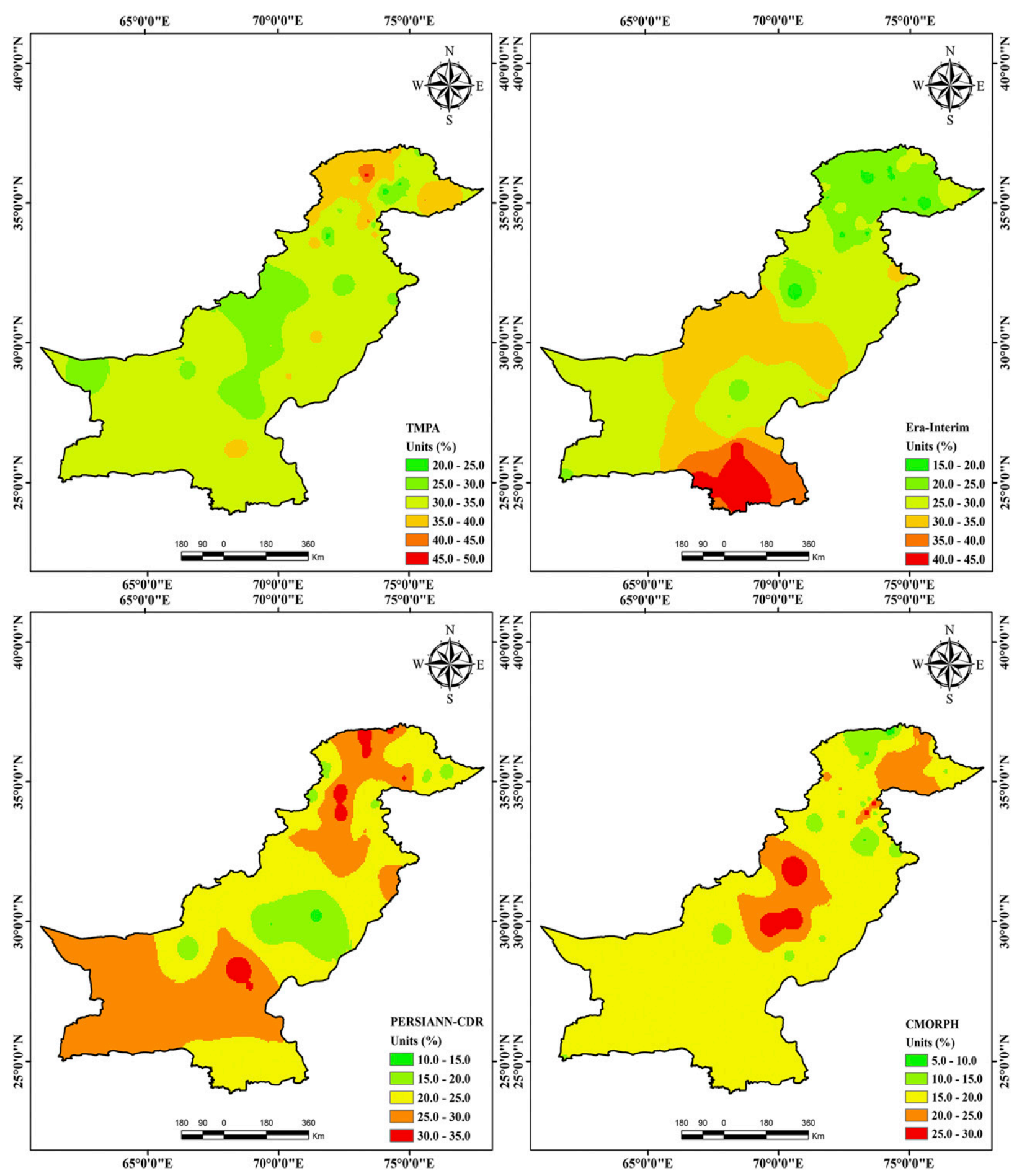

FIG. 4. Spatial distribution of relative DCBA weights of merging members in the monsoon season during 2000-15.

PERSIANN-CDR and ERA-Interim dominate other merging members during the postmonsoon season (Fig. 5). The average weights of all SPPs over entire Pakistan are 0.30 (PERSIANN-CDR), 0.27 (ERAInterim), 0.24 (TMPA), and 0.19 (CMORPH). On the regional scale, PERSIANN-CDR shows higher skills in humid (0.36) and glacial (0.29) regions. On the other hand, ERA-Interim presents higher skills in arid (0.33) and hyperarid (0.26) regions. The average weights for TMPA are ranging from a maximum of 0.29 (hyperarid region) 

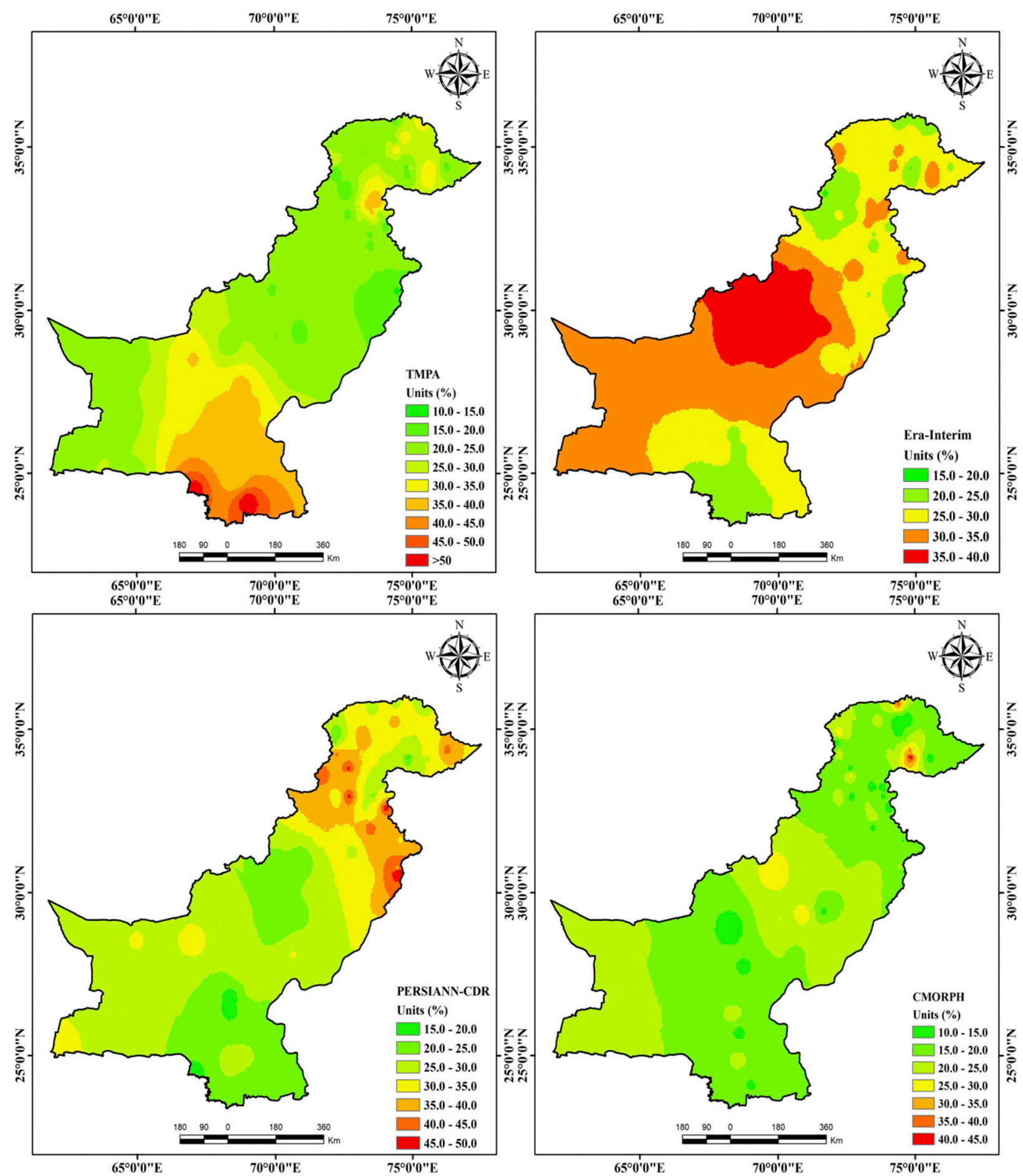

FIG. 5. Spatial distribution of relative DCBA weights of merging members in the postmonsoon season during $2000-15$.

to a minimum of 0.22 (humid region). The average weights for CMORPH are less than 0.20 in all the climate regions (maximum of 0.19 in the glacial region).

Finally, the spatial distribution of relative DCBA weights during winter season is shown in Fig. 6. During the winter season, PERSIANN-CDR and CMORPH depicted dominant skill over TMPA and ERA-Interim. The average weights of all merging members are 0.33 (PERSIANN-CDR), 0.25 (CMORPH), 0.22 (TMPA), and 0.20 (ERA-Interim). Previous studies concluded 

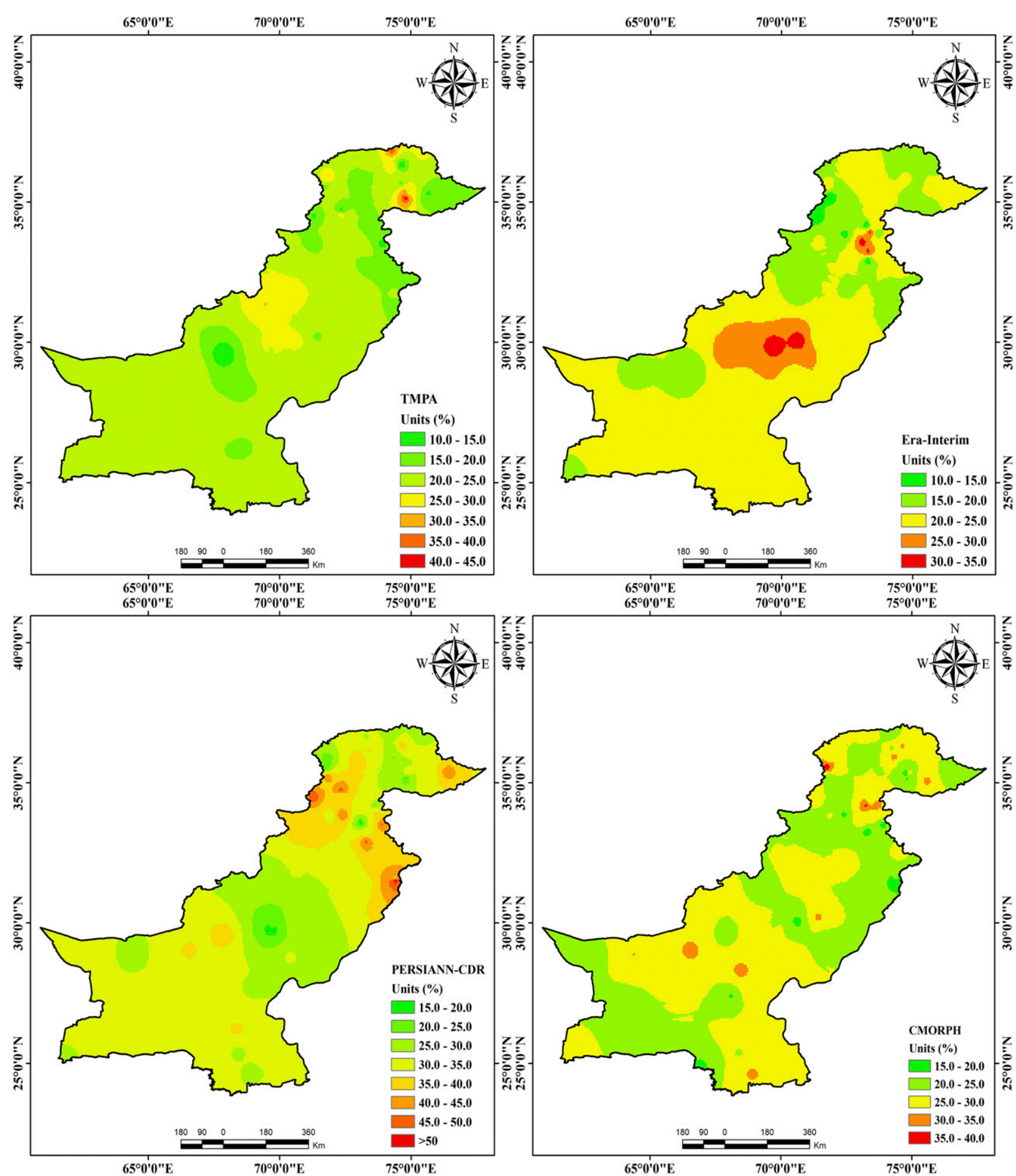

FIG. 6. Spatial distribution of relative DCBA weights of merging members in the winter season during 2000-15.

that TMPA and PERSIANN SPPs are unable to detect light precipitation and underestimate the precipitation in dry regions (Ward et al. 2011; Dinku et al. 2010; Yu et al. 2009). On the regional scale, PERSIANN-CDR shows higher average weights in humid (0.38) and hyperarid (0.31) regions. However, CMORPH shows higher weights in glacial $(0.26)$ and arid (0.25) regions. For TMPA, similar average weights (0.24) are observed in glacial and arid regions. ERA-Interim weights range from a maximum 
of 0.24 in the arid region to a minimum of 0.19 in the humid region.

\section{b. Statistical evaluation of DCBA over different climate regions}

Regional analysis of DCBA-based MMPD provided sophisticated and detailed information about the spatial distribution of statistical indices in each climate region. The analysis revealed that DCBA has significantly reduced the uncertainties and can be useful in hydrological analysis on a regional scale. Local BF is a key factor in the CBA approach, which compares the performance of different SPPs and is calculated for each pixel having at least one GPG. The regional maximum, minimum, and average values of $\log (\mathrm{BF})$ and the corresponding $\log$ maximum likelihood $[\log (\mathrm{ML})]$ are shown in Table 4 . According to the criteria defined by Jeffreys (1961), BF values indicate strong evidence (improvements) in favor of MMPD against the observed data $y$ for glacial, arid, and hyperarid regions, while it is very strong for humid regions. The average $\log (\mathrm{BF})$ value (1.85) in the glacial region is close to "very strong" evidence, which indicates significant improvements of the developed MMPD in the glacial region. The relatively lower improvements in arid and hyperarid regions are attributed to higher performance of individual SPPs in these climate regions.

Possible errors of DCBA in different climate regions may be associated with elevation, topography, climate, effects of different sensors, and retrieval algorithms used in precipitation estimates (Beighley et al. 2011). Pakistan has very complex topography that consists of glaciers, mountains, and hilly areas in the northern part and plains areas of arid and hyperarid nature in the south. The complex topography could cause strong scattering of signals in microwave (MW) measurements, especially over cold land surfaces and ice/snowdominated areas (Huffman et al. 2007; Scheel et al. 2011). Figure 7 shows the spatial distribution of daily MBE, MAE, RMSE, CC, SD, and Theil's $U$ over different climate regions of Pakistan. Figure 7 is generated by interpolating the statistical indices over all of Pakistan using ordinary kriging $(\mathrm{OK})$. OK is the most commonly used method belong to a family of estimators used to interpolate spatial data (Hengl et al. 2004; Lark et al. 2006; Rahman et al. 2019; Sun et al. 2019).

\section{1) GLACIAL REgiON}

In the glacial region, MBE (Fig. 7a) shows that DCBA has overestimated precipitation. Higher MBE is observed in the center and extreme west of the glacial region, with a higher overestimation of $+1.18 \mathrm{~mm} \mathrm{day}^{-1}$ observed at GPG GMS10. The regional average MBE value is $0.82 \mathrm{~mm} \mathrm{day}^{-1}$. The maximum and minimum MAE
TABLE 4. Local log Bayes factor $[\log (\mathrm{BF})]$ and corresponding $\log$ maximum likelihood $[\log (\mathrm{ML})]$ of clustered Bayesian model averaging (CBA) during 2000-15.

\begin{tabular}{llcc}
\hline \hline Climate region & Statistics & $\begin{array}{c}\text { Log Bayes } \\
\text { factor } \log (\mathrm{BF})\end{array}$ & $\begin{array}{c}\text { Log maximum } \\
\text { likelihood } \\
\log (\mathrm{ML})\end{array}$ \\
\hline Glacial region & Maximum & 2.32 & -4.90 \\
& Minimum & 1.14 & -8.44 \\
Humid region & Average & 1.85 & -6.64 \\
& Maximum & 3.24 & -7.84 \\
Arid region & Minimum & 1.73 & -11.79 \\
& Average & 2.50 & -10.32 \\
& Maximum & 1.94 & -4.14 \\
& Minimum & 0.53 & -9.09 \\
& Average & 1.16 & -6.95 \\
& Maximum & 2.62 & -4.28 \\
& Minimum & 0.28 & -10.36 \\
& Average & 1.01 & -5.83 \\
\hline
\end{tabular}

is observed at GPGs GMS17 $\left(2.38 \mathrm{mmday}^{-1}\right)$ and GMS16 (1.19 $\left.\mathrm{mm} \mathrm{day}^{-1}\right)$ (Fig. $\left.7 \mathrm{~b}\right)$ with an average value of $1.70 \mathrm{~mm} \mathrm{day}^{-1}$.

RMSE ranges from $2.97 \mathrm{~mm} \mathrm{day}^{-1}$ (GMS19) to $8.71 \mathrm{~mm} \mathrm{day}^{-1}$ (GMS15) for DCBA with the average of $5.92 \mathrm{~mm} \mathrm{day}^{-1}$ (Fig. 7c). Higher RMSE is observed mostly in south of the glacial region. However, the extreme north, east, and west show relatively lower RMSE. A relatively lower correlation with GPGs is observed in the glacial region as compared to other climate regions (Fig. 7d). Overall, CC ranges between 0.6 and 0.69 , with few exceptions with the regional average value of 0.63 .

$\mathrm{SD}$ (Fig. 7e) is very high in north of the glacial region, which gradually declines toward the south and northeast. Maximum and minimum SD in the glacial region is $9.21 \mathrm{~mm} \mathrm{day}^{-1}$ (GMS1) and $3.28 \mathrm{~mm} \mathrm{day}^{-1}$ (GMS5) with an average SD of $7.49 \mathrm{~mm}$ day $^{-1}$. Theil's $U$ (Fig. 7f) reflects the relatively poor performance of DCBA in the glacial region. The average Theil's $U$ value for DCBA is 0.48 with maximum and minimum Theil's $U$ of 0.55 (GMS17) and 0.41 (GMS8), respectively.

IR and PMW sensors are mostly used to estimate precipitation. IR provides information about precipitation based on the minimum temperature at the top of the cloud, while PMW sensors have information about precipitation area rather than clouds (Dinku et al. 2010). The glacial regions have relatively warm clouds, which hinder the satellite sensors' capability to detect precipitation from warm clouds because the top of the clouds would be too warm for IR thresholds to discriminate between precipitation and no-precipitation clouds (Bitew and Gebremichael 2010; Hong et al. 2007). The orographic clouds over mountains could produce heavy precipitation without much ice aloft, which the PMW algorithm cannot fully consider and may result in underestimated 

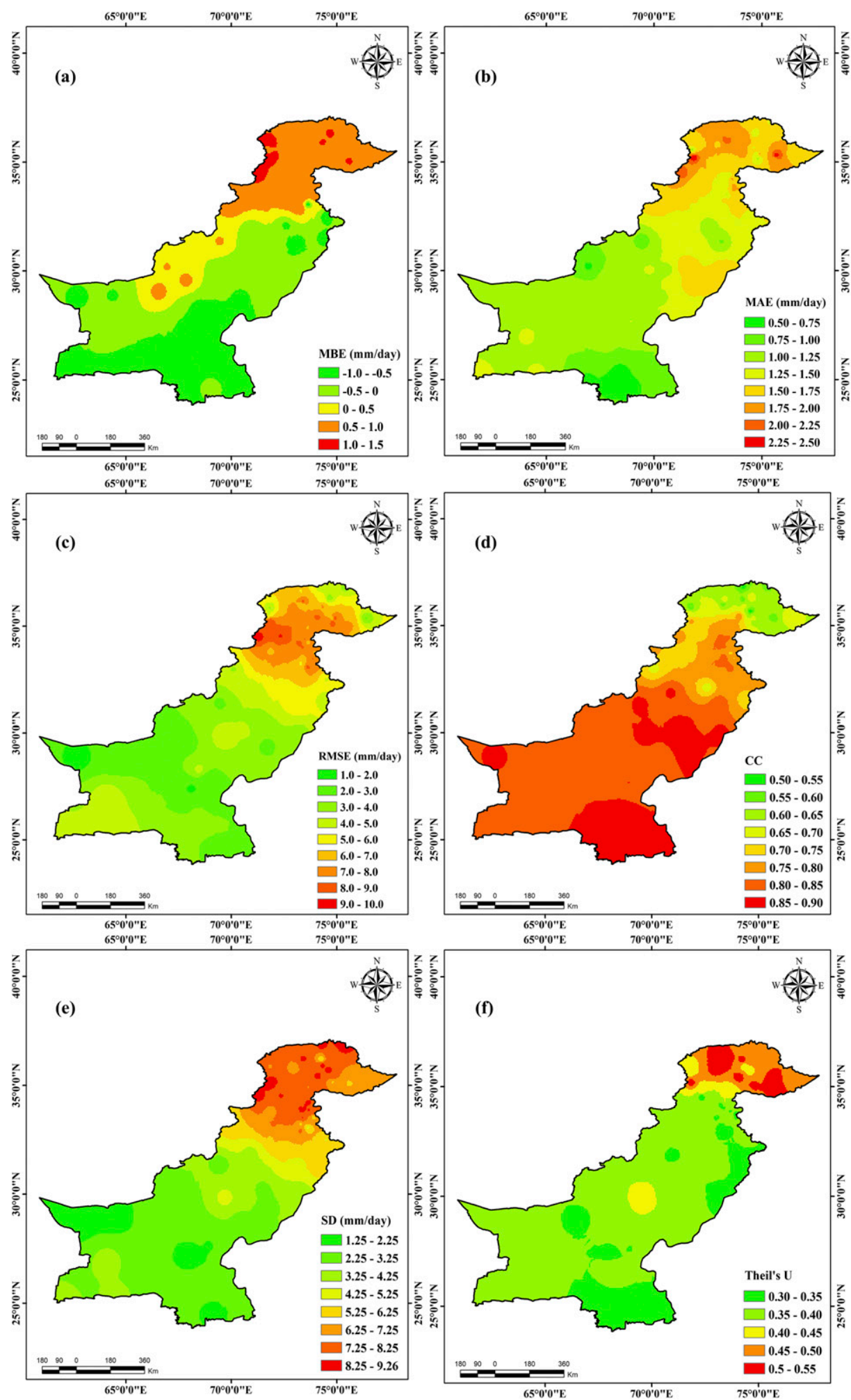

FIG. 7. Spatial distribution of DCBA daily statistical indices (a) MBE, (b) MAE, (c) RMSE, (d) CC, (e) SD, and (f) Theil's $U$ over Pakistan. 
precipitation (Dinku et al. 2010). Moreover, high vegetation coverage in the mountainous region and relatively coarser spatial resolution as compared to IR also contribute to lower accuracy of PMW sensors in detecting precipitation over mountainous regions (glacial region in the current study). The IR sensors detect precipitation from deep convection and show better performance in the summer season with smaller bias as compared to the cold season (more specifically over cold cirrus clouds). Besides, the brightness temperature and polarization properties of IR sensors vary with snow cover conditions and exposure, which in turn rely on the altitude of mountainous terrain (Amlien 2008; Scheel et al. 2011).

\section{2) HuMID REGION}

Figure 7a shows that uncertainties for DCBA decrease gradually from northwest toward the southeast of the humid region. Figure $7 \mathrm{a}$ depicts both overestimation and underestimation of precipitation in the humid region. DCBA underestimated precipitation in the southeast while it overestimated in the rest of the region. Maximum overestimation is observed at HMS4 $\left(+1.38 \mathrm{~mm} \mathrm{day}^{-1}\right)$ while maximum underestimation is at HMS34 $\left(-0.97 \mathrm{~mm} \mathrm{day}^{-1}\right)$. The average MBE in the humid region is $0.63 \mathrm{~mm}$ day $^{-1}$. Spatial distribution of MAE (Fig. 7b) over the humid region shows a similar trend compared to MBE, that is, the magnitude decreases gradually from northwest toward the southeast. Higher and lower magnitudes of MAE are observed at HMS4 (2.38 $\left.\mathrm{mm} \mathrm{day}^{-1}\right)$ and HMS40 (1.13 $\left.\mathrm{mm} \mathrm{day}^{-1}\right)$. The average MAE in the humid region is $1.60 \mathrm{~mm}$ day $^{-1}$.

Higher RMSE is observed in the north while lower RMSE occurs in the south of the humid region (Fig. 7c). RMSE shows a decreasing trend from west toward the east in most of the region, ranging from a maximum of $9.68 \mathrm{~mm} \mathrm{day}^{-1}$ (HMS11) to a minimum of $3.87 \mathrm{~mm} \mathrm{day}^{-1}$ (HMS28). Average RMSE in the region is $7.07 \mathrm{~mm} \mathrm{day}^{-1}$. Figure $7 \mathrm{~d}$ depicts that higher $\mathrm{CC}$ is observed from the center toward the east of the region. DCBA shows significant improvement in correlation with the GPGs. The maximum, minimum, and average CC of DCBA in the humid region are 0.84 (HMS13), 0.67 (HMS21), and 0.77, respectively.

SD values for DCBA range from $4.8 \mathrm{~mm} \mathrm{day}^{-1}$ (HMS30) to $9.27 \mathrm{~mm} \mathrm{day}^{-1}$ (HMS4), depicting a declining trend from northwest to southeast (Fig. 7e). The average SD in the humid region is $7.31 \mathrm{~mm} \mathrm{day}^{-1}$. Theil's $U$ (Fig. 7f) depicts a significant improvement in precipitation forecasting accuracy as compared to the glacial region. HMS1 and HMS4 show lower forecasting accuracies with Theil's $U$ greater than 0.5 , while higher accuracy is observed at HMS25 with
Theil's $U$ of 0.31 . The average value of Theil's $U$ is 0.37 , indicating a higher accuracy of DCBA in the humid region.

Heavy precipitation in the humid region may cause signal attenuation, which is significant and encountered more frequently (Villarini and Krajewski 2010). Additionally, the retrieval algorithms significantly contribute to errors associated with SPPs for highresolution estimates (AghaKouchak et al. 2009; Yan and Gebremichael 2009). The current algorithms estimate precipitation indirectly from IR brightness temperature at the top cloud and do not consider the impact of elevation and subcloud evaporation (Dinku et al. 2010; Scheel et al. 2011), which significantly affect the retrieval accuracy of SPPs ( $\mathrm{Li}$ et al. 2014). Further challenges arise from the processing scheme for microwave and IR data (Scheel et al. 2011). The calibration of retrieval algorithm using local GPG observations is indispensable, which is not just for the selection of appropriate temperature thresholds but also involves the determination of other relevant parameters (Dinku et al. 2010). External errors associated with GPGs, that is, splashing, wind effect, etc.; human-induced errors; snow dominancy; and sparse GPGs distribution, may also contribute to SPP calibration errors (Tapiador et al. 2017). These are the possible reasons that cause high magnitude errors and uncertainties of DCBA in glacial and humid climate regions.

\section{3) ARID REGION}

The spatial distribution of MBE and MAE in the arid region (Figs. 7a,b) depicts that DCBA comparatively slightly overestimated precipitation in the extreme west (mild elevated mountainous region) and underestimated precipitation in the plains areas (east and center) of the region. However, an exception is observed in the southwest of the region. The maximum and minimum MBE values for DCBA are 0.69 (AMS18) and $-0.71 \mathrm{~mm} \mathrm{day}^{-1}$ (AMS2). Average MBE for the region is $-0.13 \mathrm{~mm} \mathrm{day}^{-1}$. In contrast, MAE shows an increasing trend from west to east of the arid region. Higher MAE is observed in the southeast of the region. The average, maximum, and minimum MAE values are 1.23, 1.74 (AMS8), and $0.72 \mathrm{~mm} \mathrm{day}^{-1}$ (AMS12), respectively.

Figure $7 \mathrm{c}$ depicts a completely different trend for RMSE showing an increasing trend toward the northeast of the arid region with a dominant RMSE at the center. The maximum and minimum RMSE values are 5.93 (AMS2) and $1.75 \mathrm{~mm} \mathrm{day}^{-1}$ (AMS19), with an average value of $3.45 \mathrm{~mm} \mathrm{day}^{-1}$. Figure $7 \mathrm{~d}$ depicts that higher correlation is found in the southeast of the arid region. A significant increase in $\mathrm{CC}$ is observed in the arid region as compared to glacial and humid regions. 
Maximum and minimum $\mathrm{CC}$ values in the region are 0.87 (observed at GPGs AMS15 and AMS16) and 0.83 (observed at GPGs AMS12 and AMS13). The average $\mathrm{CC}$ in the arid region is 0.85 .

The SD gradually increases from west to east of the arid region with a dominant SD at the center (Fig. 7e). The SD ranges from 4.63 (AMS2) to $1.77 \mathrm{~mm} \mathrm{day}^{-1}$ (AMS19) with an average value of $3.28 \mathrm{~mm} \mathrm{day}^{-1}$. Further, the Theil's $U$ depicts better forecasting accuracy at the extreme west and east while it is comparatively worse in the middle of the arid region (Fig. 7f). Theil's $U$ for DCBA is lower than 0.4 over most of the GPGs except AMS10 (0.43) and AMS11 (0.44) with an average value of 0.36 .

\section{4) HYPERARID REGION}

MBE results (Fig. 7a) indicate that DCBA underestimated precipitation in the whole hyperarid region. The performance of DCBA has significantly improved in the hyperarid region as compared to other climate regions. The figure depicts higher underestimation in the southwest of the region. The maximum, minimum, and average MBE values are -0.85 (HAMS3), -0.36 (HAMS21), and $-0.63 \mathrm{~mm} \mathrm{day}^{-1}$, respectively. MAE (Fig. 7b) in the region ranges between 0.60 (HAMS18) and $1.41 \mathrm{~mm} \mathrm{day}^{-1}$ (HAMS24) with an average value of $1.06 \mathrm{~mm} \mathrm{day}^{-1}$. Higher MAE is observed in the southwest of the hyperarid region, which gradually reduces toward the east.

RMSE shows a similar trend compared to the MAE (Fig. 7c), that is, higher (maximum $4.94 \mathrm{~mm} \mathrm{day}^{-1}$ at HAMS22) in the southwest while lower (minimum $1.49 \mathrm{~mm} \mathrm{day}^{-1}$ at HAMS8) in the northwest of the hyperarid region. RMSE gradually declines from the southwest toward the north and east with an average value of $3.15 \mathrm{~mm} \mathrm{day}^{-1}$. From Fig. $7 \mathrm{~d}$, correlation with GPGs is significantly increased as compared to other climate regions. The figure depicts better performance in the southeast of the region. Overall, average $\mathrm{CC}$ in the region is 0.84 . Lower correlation is observed in the southwest of the region while higher $\mathrm{CC}$ occurs in the southeast. Minimum and maximum $\mathrm{CC}$ values are 0.80 (HAMS10) and 0.88 (HAMS11).

Figure 7e depicts higher SD in the southwest and lower SD in the northwest of the region. Average $\mathrm{SD}$ in the region is $2.59 \mathrm{~mm} \mathrm{day}^{-1}$, and the maximum and minimum SD values are 3.72 (HAMS10) and $1.27 \mathrm{~mm} \mathrm{day}^{-1}$ (HAMS8), respectively. Moreover, Theil's $U$ shows higher forecasting accuracy in the southeast of the region while lower accuracy occurs in the southwest (Fig. 7f). Maximum and minimum Theil's $U$ in the region is 0.40 (HAMS24) and 0.33 (HAMS21), respectively, with an average value of 0.36 .
Previous studies conducted over Pakistan demonstrated the higher performance of SPPs in the plains and low altitude regions (such as hyperarid region) as compared to elevated regions (Hussain et al. 2018; Iqbal and Athar 2018; Rahman et al. 2018). Therefore, the uncertainties in DCBA reduce from a maximum in the glacial region to a minimum in the hyperarid region with the highest accuracies and correlation in low altitude regions.

\section{c. Evaluation of DCBA on a seasonal scale}

The average DCBA weights (Fig. 8) of the representative GPGs in each climate region are plotted against the day of the year (DOY). Representative GPG weight values are close to the average temporal distribution of DBMA weights in the corresponding climate region. The representative stations for glacial, humid, arid, and hyperarid regions are GMS10, HMS17, AMS13, and HAMS17, respectively. In Fig. 8, the $y$ axis represents the cumulative weights of the merged members, that is, TMPA, PERSIANN-CDR, ERA-Interim, and CMORPH. The sum of weights at each representative station on each day must be equal to 1 . Therefore, the thickness of each band represents weights of the corresponding merging member. For example, the cumulative weights for CMORPH in the glacial region lie between 0.8 and 1 (with few exceptions) with an average thickness of 0.2 , which represents that the weight of CMORPH is 0.2 on average. Similarly, the average weights of TMPA, PERSIANN-CDR, and ERA-Interim are $0.35,0.25$, and 0.2 , respectively.

The figure shows that DCBA captures the monsoon precipitation (DOY 181-273) reasonably well in all climate regions. However, relatively higher PERSIANNCDR and ERA-Interim weights are observed in the glacial region at the beginning of the winter seasons (DOY 334-365). In the humid and arid regions, relatively higher fluctuations of weights of each merging member are observed in the midwinter (DOY 8-30) and premonsoon (DOY 90-115) seasons. A similar phenomenon is also observed in the hyperarid region, where the TMPA and ERA-Interim weights are relatively higher at the end of the year (winter season).

Table 5 represents the seasonal evaluation of DCBA across all four climate regions. The results show that DCBA performance is subjected to the impacts of precipitation intensity/magnitude and elevation. DCBA depicts relatively poor performance in heavy precipitation seasons, that is, monsoon and premonsoon, while better performance in mild (postmonsoon) to low (winter) precipitation seasons. MBE results depict overestimation in the monsoon and premonsoon 

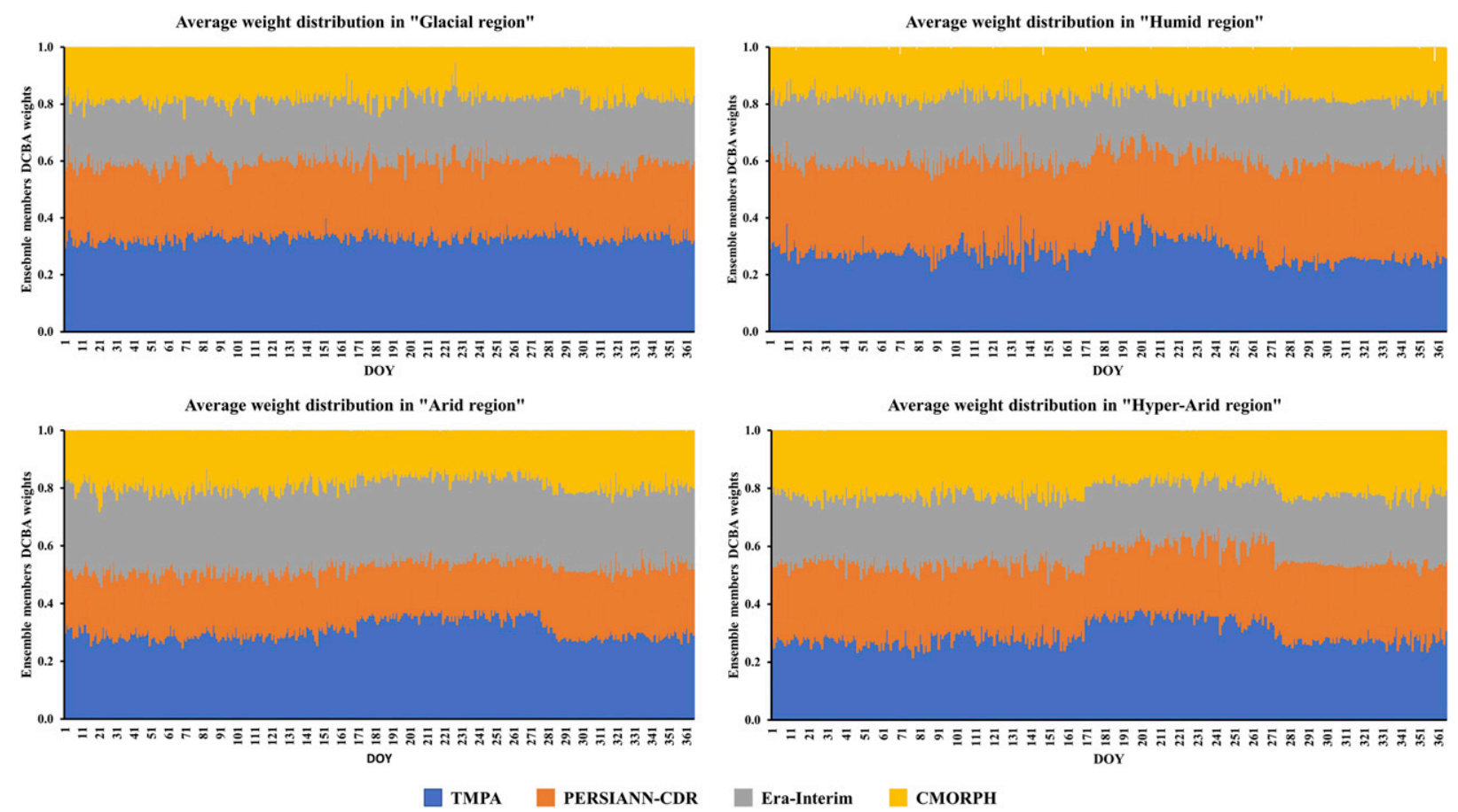

FIG. 8. Distribution of DCBA weights against the DOY in all the climate regions.

seasons in all climate regions except the hyperarid region (underestimation). However, DCBA underestimated precipitation in the postmonsoon and winter seasons except for the glacial region. All other statistical indices confirm the higher skills of DCBA over low elevated climate regions in mild to low precipitation events.

\section{d. Comparison of the performance of DCBA and merging members}

Table 6 shows the performance evaluation of DCBA and four merging members, that is, TMPA, ERA-Interim,
PERSIANN-CDR, and CMORPH against 102 GPGs across all four climate regions. The results show that DCBA outperformed all the individual merging members in all climate regions. Among the selected SPPs, TMPA presents better performance showing higher forecasting accuracies, relatively small uncertainties, and higher correlation with GPGs. In contrast, CMORPH presents the worst performance among all the SPPs across all climate regions. The table shows that DCBA has significantly reduced the uncertainties of individual SPPs. Comparison of DCBA with TMPA shows that MBE is reduced by $57 \%$,

TABLE 5. Seasonal evaluation of DCBA on daily temporal scale over 102 GPGs during 2000-15.

\begin{tabular}{|c|c|c|c|c|c|c|c|}
\hline Season & Climate region & $\operatorname{MBE}\left(\mathrm{mm}\right.$ day $\left.^{-1}\right)$ & $\operatorname{MAE}\left(\mathrm{mm} \mathrm{day}^{-1}\right)$ & $\operatorname{RMSE}\left(\mathrm{mm} \mathrm{day}^{-1}\right)$ & $\mathrm{CC}$ & $\mathrm{SD}\left(\mathrm{mm}\right.$ day $\left.^{-1}\right)$ & Theil's $U$ \\
\hline \multirow[t]{4}{*}{ Winter } & Glacial & 0.671 & 1.65 & 5.75 & 0.64 & 6.80 & 0.46 \\
\hline & Humid & 0.60 & 1.58 & 6.82 & 0.79 & 6.94 & 0.36 \\
\hline & Arid & -0.11 & 0.98 & 3.19 & 0.86 & 3.28 & 0.35 \\
\hline & Hyperarid & -0.63 & 0.93 & 3.82 & 0.86 & 2.43 & 0.34 \\
\hline \multirow[t]{4}{*}{ Premonsoon } & Glacial & 0.95 & 1.72 & 6.05 & 0.62 & 8.18 & 0.50 \\
\hline & Humid & 0.67 & 1.65 & 7.06 & 0.75 & 7.77 & 0.40 \\
\hline & Arid & 0.14 & 1.23 & 3.97 & 0.85 & 3.71 & 0.38 \\
\hline & Hyperarid & -0.63 & 1.13 & 3.46 & 0.83 & 2.99 & 0.37 \\
\hline \multirow[t]{4}{*}{ Monsoon } & Glacial & 1.09 & 2.39 & 6.31 & 0.60 & 9.04 & 0.54 \\
\hline & Humid & 0.76 & 2.13 & 7.60 & 0.71 & 8.95 & 0.43 \\
\hline & Arid & 0.17 & 1.85 & 4.25 & 0.81 & 4.04 & 0.41 \\
\hline & Hyperarid & -0.66 & 1.31 & 4.01 & 0.83 & 3.41 & 0.40 \\
\hline \multirow[t]{4}{*}{ Postmonsoon } & Glacial & 0.57 & 1.04 & 5.58 & 0.67 & 5.97 & 0.44 \\
\hline & Humid & -0.58 & 1.03 & 6.79 & 0.83 & 5.57 & 0.33 \\
\hline & Arid & -0.41 & 0.85 & 2.38 & 0.86 & 2.08 & 0.31 \\
\hline & Hyperarid & -0.49 & 0.81 & 2.30 & 0.87 & 1.52 & 0.32 \\
\hline
\end{tabular}


TABLE 6. Comparison of daily average statistical indices of DCBA against four merging members at 102 GPGs during 2000-15.

\begin{tabular}{|c|c|c|c|c|c|c|c|}
\hline Climate region & Datasets & $\operatorname{MBE}\left(\mathrm{mm} \mathrm{day}^{-1}\right)$ & $\operatorname{MAE}\left(\mathrm{mm} \mathrm{day}^{-1}\right)$ & $\operatorname{RMSE}\left(\mathrm{mm} \mathrm{day}^{-1}\right)$ & $\mathrm{CC}$ & $\mathrm{SD}\left(\mathrm{mm} \mathrm{day}^{-1}\right)$ & Theil's $U$ \\
\hline \multirow[t]{5}{*}{ Glacial } & DCBA & 0.82 & 1.70 & 5.92 & 0.63 & 7.49 & 0.49 \\
\hline & TMPA & 1.91 & 2.79 & 10.83 & 0.45 & 12.63 & 0.56 \\
\hline & ERA-Interim & 2.27 & 3.25 & 11.39 & 0.38 & 13.04 & 0.64 \\
\hline & PERSIANN-CDR & 2.14 & 3.01 & 11.01 & 0.42 & 12.78 & 0.60 \\
\hline & CMORPH & 2.51 & 3.60 & 11.87 & 0.34 & 13.09 & 0.67 \\
\hline \multirow[t]{5}{*}{ Humid } & DCBA & 0.63 & 1.59 & 7.16 & 0.77 & 7.34 & 0.38 \\
\hline & TMPA & 1.54 & 2.80 & 11.62 & 0.59 & 11.13 & 0.48 \\
\hline & ERA-Interim & 1.86 & 3.34 & 11.58 & 0.52 & 11.67 & 0.54 \\
\hline & PERSIANN-CDR & 1.65 & 3.05 & 11.32 & 0.56 & 11.40 & 0.51 \\
\hline & CMORPH & 2.04 & 3.65 & 11.84 & 0.49 & 11.93 & 0.58 \\
\hline \multirow[t]{5}{*}{ Arid } & DCBA & -0.13 & 1.23 & 3.45 & 0.85 & 3.28 & 0.37 \\
\hline & TMPA & -0.36 & 3.15 & 7.28 & 0.71 & 6.69 & 0.46 \\
\hline & ERA-Interim & -0.53 & 3.65 & 7.91 & 0.63 & 7.18 & 0.54 \\
\hline & PERSIANN-CDR & 0.46 & 3.40 & 7.64 & 0.67 & 6.94 & 0.50 \\
\hline & CMORPH & -0.62 & 3.91 & 8.18 & 0.61 & 7.41 & 0.57 \\
\hline \multirow[t]{5}{*}{ Hyperarid } & DCBA & -0.63 & 1.06 & 3.15 & 0.84 & 2.59 & 0.36 \\
\hline & TMPA & -1.51 & 2.32 & 5.97 & 0.76 & 6.66 & 0.46 \\
\hline & ERA-Interim & -2.00 & 2.82 & 6.53 & 0.68 & 7.17 & 0.53 \\
\hline & PERSIANN-CDR & -1.76 & 2.57 & 6.24 & 0.72 & 6.91 & 0.50 \\
\hline & CMORPH & -2.25 & 3.04 & 6.84 & 0.65 & 7.43 & 0.57 \\
\hline
\end{tabular}

$59.1 \%, 63.88 \%$, and $58.28 \%$ in glacial, humid, arid, and hyperarid regions, respectively. Similarly, MAE is reduced by $39 \%, 43.21 \%, 60.95 \%$, and $54.31 \%$ while the RMSE declination rate is $45.34 \%, 38.38 \%, 52.61 \%$, and $47.24 \%$ in glacial, humid, arid, and hyperarid regions, respectively. A higher increase in $\mathrm{CC}$ is observed in the glacial region $(28.57 \%)$, while a higher increase in forecasting accuracy (Theil's $U$ ) is observed in the hyperarid region $(21.74 \%)$.

\section{Discussion}

Precise estimation of precipitation is a fundamental element for hydrological modeling and climate change impact studies. The hydrological processes are significantly impacted by spatial and temporal variability of precipitation. However, the higher spatial and temporal variability of precipitation is a challenging task over the complex topography and diverse climate of Pakistan (Rahman et al. 2018). Due to the sparse distribution of GPGs, it is difficult to measure the spatial and temporal variability of precipitation. As an alternative, SPPs provide the homogenous precipitation estimates on regional and global scales. With the rapid development of remote sensing techniques and continuous improvements in satellitebased retrieval algorithms over the last three decades, the quantitative estimation of precipitation using SPPs is cost effective and reliable at regional and global scales (Hobouchian et al. 2017; Tapiador et al. 2012).

However, all the SPPs are subjected to uncertainties resulting from retrieval algorithms. To minimize uncertainties associated with individual SPPs, researchers have focused on merging the SPPs to obtain high-quality
MMPDs (Boudevillain et al. 2016; Ma et al. 2018a; Massari et al. 2018; Muhammad et al. 2018; Rahman et al. 2018). Very limited studies have focused on developing MMPDs over Pakistan. Rahman et al. (2018) and Muhammad et al. (2018) evaluated MMPDs across Pakistan. Both studies reported a significant reduction in uncertainties and improvement in agreement with the GPGs as compared to individual SPPs. Besides the significant improvement, all the MMPDs are subjected to high uncertainties at high elevation and high magnitude/intensity precipitation (Ma et al. 2018a; Muhammad et al. 2018; Rahman et al. 2018). Shen et al. (2014) and (Ma et al. 2018a) also reported that precipitation uncertainty increased rapidly at an elevation greater than $4000 \mathrm{~m}$.

Ma et al. (2018a) merged four precipitation datasets, that is, TMPA 3B42RT, TMPA 3B42V7, CMORPH, and PERSIANN-CDR, using the the DBMA scheme. The MMPD has $0.25^{\circ}$ spatial resolution with 2007-12 temporal time scale, evaluated over the Tibetan Plateau (TP). The DBMA MMPD is evaluated spatially and seasonally across the TP. In their study, PERSIANNCDR (0.376) showed higher skill, especially in the winter season. Minimum weights were observed for TMPA $3 \mathrm{~B} 42 \mathrm{RT}$ and $3 \mathrm{~B} 42 \mathrm{~V} 7$ with average weights of 0.179 and 0.189. It was demonstrated that DBMA significantly reduced the errors in comparison with individual SPP. In contrast, TMPA and PERSIANN-CDR presented higher skill in DCBA with average weights of 0.29 and 0.27 , respectively. TMPA shows higher skill in the glacial region (0.34) while PERSIANN-CDR was higher in the humid region (0.32). On a seasonal scale, 
TMPA has higher weights in premonsoon $(0.41)$ and monsoon (0.35) seasons. Moreover, PERSIANN-CDR presented higher weights in the postmonsoon season (0.36) and winter (0.38), respectively. The DCBA algorithm in the glacial region (northern area of Pakistan) was compared with DBMA in the TP (as the glacial region and TP are adjacent to each other). The comparison revealed the supremacy of DCBA in the complex terrain (elevation $>4000 \mathrm{~m}$ ) in terms of bias, RMSE, and other statistical indices.

Although DCBA has significantly reduced the uncertainties in all climate regions over complex topography in Pakistan, high discrepancies are still observed at high elevation (glacial and humid regions). This may be due to the fact that the quality of MMPD (DCBA) is subjected to the accuracy of merging members (SPPs), which are used to calculate DCBA weights (Sloughter et al. 2007). Therefore, the relatively poor performance of DCBA at high altitude regions is attributed to lowquality SPP data. Besides topographic dependency of SPPs, the dominancy of snow at high elevation affects the performance of SPPs (Tapiador et al. 2017). Furthermore, there are a number of reasons associated with GPGs such as the wind effect, evaporation from GPGs, human-induced errors, splashing effect, seasonal effects, etc., which also contribute to higher uncertainties at high elevation. The forecasting accuracy determined through Theil's $U$ and correlation coefficient confirms the high performance of DCBA at mild/low-altitude climate regions (arid and hyperarid). Based on spatial and seasonal evaluation of DCBA, our study supports the findings of previous similar studies (Ma et al. 2018a; Muhammad et al. 2018; Rahman et al. 2018). Moreover, DCBA addressed the nonregionality of BMA using the Bayes theorem and has a potential for regional-scale hydrological modeling.

\section{Conclusions}

This study presented an application of the dynamic clustered Bayesian model averaging (DCBA) algorithm to develop a merged multisatellite precipitation dataset (MMPD) from four different satellite precipitation products (SPPs). The MMPD was developed and evaluated in Pakistan having complex topography, diverse climate, and sparsely distributed ground precipitation gauges (GPGs). Four extensively evaluated merging members (SPPs), including TMPA 3B42V7, PERSIANNCDR, ERA-Interim, and CMORPH, are selected to develop the MMPD during 2000-15. The MMPD is evaluated across four different climate regions under daily and seasonal temporal scales. The key findings from the current study are given below:
1) DCBA proves its capability to address the nonregionality of traditional Bayesian model averaging (BMA) algorithm. The statistical evaluation using MBE, MAE, RMSE, CC, SD, and Theil's $U$ confirms the higher regional performance of DCBA.

2) DCBA outperforms all the merging members, and TMPA presents better performance among all selected SPPs. The average improvement of DCBA in comparison with TMPA is $59.56 \%$ (MBE), $49.37 \%$ (MAE), 45.89\% (RMSE), 19.48\% (CC), 46.7\% (SD), and $18.66 \%$ (Theil's $U$ ).

3) Forecasting accuracy determined using Theil's $U$ demonstrates the better performance of DCBA with average values of $0.49,0.38,0.37$, and 0.36 in glacial, humid, arid, and hyperarid regions, respectively.

4) DCBA presents a higher correlation with ground precipitation gauges (GPGs). The values of $\mathrm{CC}$ in glacial, humid, arid, and hyperarid regions are 0.69 , $0.77,0.85$, and 0.84 , respectively.

5) DCBA demonstrates its capability to capture the precipitation trends effectively across all climate regions, even high precipitation during monsoon and premonsoon seasons. In most of the cases, TMPA and PERSIANN-CDR show higher skills.

6) The seasonal evaluation reveals the dependency of DCBA on precipitation intensity/magnitude and elevation. Relatively lower skills (accuracies) are observed in high precipitation seasons and high elevation.

7) Overall, DCBA has significantly reduced the uncertainties as compared to the individual merged members on regional and seasonal scales. DCBA has the potential for further regional-scale hydrological studies.

Acknowledgments. The authors would like to acknowledge the Pakistan Meteorological Department (PMD) and Water and Power Development Authority (WAPDA) for providing the gauge precipitation data and are grateful to SPPs developers. This research was supported by the National Natural Science Foundation of China (Grants 51779119, 51839006, and 51479090). Valuable comments from the editor and anonymous reviewers are greatly appreciated, which have significantly improved the quality of the manuscript. The authors are thankful to Zubair Hassan for reviewing the manuscript and addressing the grammatical and spelling mistakes.

\section{REFERENCES}

AghaKouchak, A., N. Nasrollahi, and E. Habib, 2009: Accounting for uncertainties of the TRMM satellite estimates. Remote Sens., 1, 606-619, https://doi.org/10.3390/rs1030606.

Almazroui, M., 2011: Calibration of TRMM rainfall climatology over Saudi Arabia during 1998-2009. Atmos. Res., 99, 400414, https://doi.org/10.1016/j.atmosres.2010.11.006. 
Amlien, J., 2008: Remote Sensing of Snow with Passive Microwave Radiometers-A Review of Current Algorithms. Norsk Regnesentral Report 1019, 52 pp.

Anjum, M. N., Y. Ding, D. Shangguan, M. W. Ijaz, and S. Zhang, 2016: Evaluation of high-resolution satellite-based real-time and post-real-time precipitation estimates during 2010 extreme flood event in Swat River Basin, Hindukush region. $A d v$. Meteor., 2016, 2604980, http://dx.doi.org/10.1155/2016/2604980.

Ashouri, H., and Coauthors, 2015: PERSIANN-CDR: Daily precipitation climate data record from multisatellite observations for hydrological and climate studies. Bull. Amer. Meteor. Soc., 96, 69-83, https://doi.org/10.1175/BAMS-D-13-00068.1.

Behrangi, A., and Coauthors, 2011: Hydrologic evaluation of satellite precipitation products over a mid-size basin. J. Hydrol., 397, 225-237, https://doi.org/10.1016/j.jhydrol.2010.11.043.

Beighley, R. E., and Coauthors, 2011: Comparing satellite derived precipitation datasets using the Hillslope River Routing (HRR) model in the Congo River Basin. Hydrol. Processes, 25, 3216-3229, https://doi.org/10.1002/hyp.8045.

Berrisford, P., and Coauthors, 2011: Atmospheric conservation properties in ERA-Interim. Quart. J. Roy. Meteor. Soc., 137, 1381-1399, https://doi.org/10.1002/qj.864.

Bitew, M. M., and M. Gebremichael, 2010: Evaluation through independent measurements: Complex terrain and humid tropical region in Ethiopia. Satellite Rainfall Applications for Surface Hydrology, M. Gebremichael and F. Hossain, Eds., Springer, 205-214.

Bliemel, F., 1973: Theil's forecast accuracy coefficient: A clarification. J. Mark. Res., 10, 444-446, https://doi.org/10.1177/ 002224377301000413.

Boudevillain, B., G. Delrieu, A. Wijbrans, and A. Confoland, 2016: A high-resolution rainfall re-analysis based on radar-raingauge merging in the Cévennes-Vivarais region, France. J. Hydrol., 541, 14-23, https://doi.org/10.1016/ j.jhydrol.2016.03.058.

Chen, F., and X. Li, 2016: Evaluation of IMERG and TRMM 3B43 monthly precipitation products over mainland China. Remote Sens., 8, 472, https://doi.org/10.3390/rs8060472.

Dee, D. P., and Coauthors, 2011: The ERA-Interim reanalysis: Configuration and performance of the data assimilation system. Quart. J. Roy. Meteor. Soc., 137, 553-597, https:// doi.org/10.1002/qj.828.

Derin, Y., and K. K. Yilmaz, 2014: Evaluation of multiple satellite-based precipitation products over complex topography. J. Hydrometeor., 15, 1498-1516, https://doi.org/10.1175/ JHM-D-13-0191.1.

Dinku, T., S. J. Connor, and P. Ceccato, 2010. Comparison of CMORPH and TRMM-3B42 over mountainous regions of Africa and South America. Satellite Rainfall Applications for Surface Hydrology, M. Gebremichael and F. Hossain, Eds., Springer, 193-204.

Duan, Q., and T. J. Phillips, 2010: Bayesian estimation of local signal and noise in multimodel simulations of climate change. J. Geophys. Res., 115, D18123, https://doi.org/10.1029/2009JD013654.

Ebert, E. E., 2007. Methods for verifying satellite precipitation estimates. Measuring Precipitation from Space, V. Levizzani, P. Bauer, and F. J. Turk, Eds., Springer, 345-356.

Fang, J., and Coauthors, 2013: Spatial downscaling of TRMM precipitation data based on the orographical effect and meteorological conditions in a mountainous area. Adv. Water Resour., 61, 42-50, https://doi.org/10.1016/j.advwatres.2013.08.011.

Hamill, T. M., 2007: Comments on "calibrated surface temperature forecasts from the Canadian ensemble prediction system using
Bayesian model averaging." Mon. Wea. Rev., 135, 4226-4230, https://doi.org/10.1175/2007MWR1963.1.

Hengl, T., G. B. M. Heuvelink, and A. Stein, 2004: A generic framework for spatial prediction of soil variables based on regression-kriging. Geoderma, 120, 75-93, https://doi.org/ 10.1016/j.geoderma.2003.08.018.

Hirpa, F. A., M. Gebremichael, and T. Hopson, 2010: Evaluation of high-resolution satellite precipitation products over very complex terrain in Ethiopia. J. Appl. Meteor. Climatol., 49, 1044-1051, https://doi.org/10.1175/2009JAMC2298.1.

Hobouchian, M. P., P. Salio, Y. García Skabar, D. Vila, and R. Garreaud, 2017: Assessment of satellite precipitation estimates over the slopes of the subtropical Andes. Atmos. Res., 190, 43-54, https://doi.org/10.1016/j.atmosres.2017.02.006.

Hong, Y., K.-L. Hsu, S. Sorooshian, and X. Gao, 2004: Precipitation estimation from remotely sensed imagery using an artificial neural network cloud classification system. J. Appl. Meteor., 43, 1834-1853, https://doi.org/10.1175/JAM2173.1.

—, D. Gochis, J. Cheng, K. Hsu, and S. Sorooshian, 2007: Evaluation of PERSIANN-CCS rainfall measurement using the NAME event rain gauge network. J. Hydrometeor., 8,469 482, https://doi.org/10.1175/JHM574.1.

Huffman, G. J., and Coauthors, 2007: The TRMM Multisatellite Precipitation Analysis (TMPA): Quasi-global, multiyear, combined-sensor precipitation estimates at fine scales. J. Hydrometeor., 8, 38-55, https://doi.org/10.1175/JHM560.1.

Hussain, Y., and Coauthors, 2018: Performance of CMORPH, TMPA, and PERSIANN rainfall datasets over plain, mountainous, and glacial regions of Pakistan. Theor. Appl. Climatol., 131, 11191132, https://doi.org/10.1007/s00704-016-2027-z.

Iqbal, M. F., and H. Athar, 2018: Validation of satellite based precipitation over diverse topography of Pakistan. Atmos. Res., 201, 247-260, https://doi.org/10.1016/j.atmosres.2017.10.026.

Jeffreys, H., 1961: Theory of Probability. Oxford University Press, $470 \mathrm{pp}$.

Joyce, R. J., J. E. Janowiak, P. A. Arkin, and P. Xie, 2004: CMORPH: A method that produces global precipitation estimates from passive microwave and infrared data at high spatial and temporal resolution. J. Hydrometeor., 5, 487-503, https://doi.org/10.1175/ 1525-7541(2004)005<0487:CAMTPG > 2.0.CO;2.

Kass, R. E., and A. E. Raftery, 1995: Bayes factors. J. Amer. Stat. Assoc., 90, 773-795, https://doi.org/10.1080/01621459.1995.10476572.

Khan, S. I., and Coauthors, 2014: Evaluation of three high-resolution satellite precipitation estimates: Potential for monsoon monitoring over Pakistan. Adv. Space Res., 54, 670-684, https://doi.org/ 10.1016/j.asr.2014.04.017.

Kidd, C., and G. Huffman, 2011: Global precipitation measurement. Meteor. Appl., 18, 334-353, https://doi.org/10.1002/met.284.

Lark, R. M., B. R. Cullis, and S. J. Welham, 2006: On spatial prediction of soil properties in the presence of a spatial trend: The empirical best linear unbiased predictor (E-BLUP) with REML. Eur. J. Soil Sci., 57, 787-799, https://doi.org/10.1111/j.1365-2389.2005.00768.x.

Li, X., Q. Zhang, and C.-Y. Xu, 2014: Assessing the performance of satellite-based precipitation products and its dependence on topography over Poyang Lake basin. Theor. Appl. Climatol., 115, 713-729, https://doi.org/10.1007/s00704-013-0917-x.

Ma, Y., and Coauthors, 2018a: Performance of optimally merged multisatellite precipitation products using the dynamic Bayesian model averaging scheme over the Tibetan Plateau. J. Geophys. Res. Atmos., 123, 814-834, https:// doi.org/10.1002/2017JD026648.

, and Coauthors, 2018b: Comprehensive evaluation of ensemble multi-satellite precipitation dataset using the dynamic Bayesian 
model averaging scheme over the Tibetan Plateau. J. Hydrol., 556, 634-644, https://doi.org/10.1016/j.jhydrol.2017.11.050.

Maggioni, V., P. C. Meyers, and M. D. Robinson, 2016: A review of merged high-resolution satellite precipitation product accuracy during the Tropical Rainfall Measuring Mission (TRMM) era. J. Hydrometeor., 17, 1101-1117, https://doi.org/ 10.1175/JHM-D-15-0190.1.

Mahmoud, M. T., M. A. Al-Zahrani, and H. O. Sharif, 2018: Assessment of global precipitation measurement satellite products over Saudi Arabia. J. Hydrol., 559, 1-12, https:// doi.org/10.1016/j.jhydrol.2018.02.015.

Massari, C., S. Camici, L. Ciabatta, and L. Brocca, 2018: Exploiting satellite-based surface soil moisture for flood forecasting in the Mediterranean area: State update versus rainfall correction. Remote Sens., 10, 292, https://doi.org/ 10.3390/rs10020292.

Miao, C., H. Ashouri, K.-L. Hsu, S. Sorooshian, and Q. Duan, 2015: Evaluation of the PERSIANN-CDR daily rainfall estimates in capturing the behavior of extreme precipitation events over China. J. Hydrometeor., 16, 1387-1396, https://doi.org/10.1175/ JHM-D-14-0174.1.

Moazami, S., S. Golian, Y. Hong, C. Sheng, and M. R. Kavianpour, 2016: Comprehensive evaluation of four high-resolution satellite precipitation products under diverse climate conditions in Iran. Hydrol. Sci. J., 61, 420-440, https://doi.org/10.1080/ 02626667.2014.987675.

Muhammad, W., H. Yang, H. Lei, A. Muhammad, and D. Yang, 2018: Improving the regional applicability of satellite precipitation products by ensemble algorithm. Remote Sens., 10, 577, https://doi.org/10.3390/rs10040577.

Raftery, A. E., T. Gneiting, F. Balabdaoui, and M. Polakowski, 2005: Using Bayesian model averaging to calibrate forecast ensembles. Mon. Wea. Rev., 133, 1155-1174, https://doi.org/ 10.1175/MWR2906.1.

Rahman, K. U., S. Shang, M. Shahid, and J. Li, 2018: Developing an ensemble precipitation algorithm from satellite products and its topographical and seasonal evaluations over Pakistan. Remote Sens., 10, 1835, https://doi.org/10.3390/rs10111835.

,$--1-$, and Y. Wen, 2019: Performance assessment of SM2RAIN-CCI and SM2RAIN-ASCAT precipitation products over Pakistan. Remote Sens., 11, 2040, https://doi.org/10.3390/ rs11172040.

Ringard, J., M. Becker, F. Seyler, and L. Linguet, 2015: Temporal and spatial assessment of four satellite rainfall estimates over French Guiana and North Brazil. Remote Sens., 7, 1644116459 , https://doi.org/10.3390/rs71215831.

Romilly, T. G., and M. Gebremichael, 2011: Evaluation of satellite rainfall estimates over Ethiopian river basins. Hydrol. Earth Syst. Sci., 15, 1505-1514, https://doi.org/10.5194/hess-15-1505-2011.

Scheel, M., and Coauthors, 2011: Evaluation of TRMM Multisatellite Precipitation Analysis (TMPA) performance in the Central Andes region and its dependency on spatial and temporal resolution. Hydrol. Earth Syst. Sci., 15, 2649-2663, https://doi.org/10.5194/hess-15-2649-2011.

Shen, Y., and Coauthors, 2014: Uncertainty analysis of five satellite-based precipitation products and evaluation of three optimally merged multi-algorithm products over the Tibetan Plateau. Int. J. Remote Sens., 35, 6843-6858, https://doi.org/ 10.1080/01431161.2014.960612.

Sloughter, J. M. L., A. E. Raftery, T. Gneiting, and C. Fraley, 2007: Probabilistic quantitative precipitation forecasting using Bayesian model averaging. Mon. Wea. Rev., 135, 3209-3220, https://doi.org/ 10.1175/MWR3441.1.
Sorooshian, S., and Coauthors, 2011: Advanced concepts on remote sensing of precipitation at multiple scales. Bull. Amer. Meteor. Soc., 92, 1353-1357, https://doi.org/10.1175/2011BAMS3158.1.

Sun, R., H. Yuan, X. Liu, and X. Jiang, 2016: Evaluation of the latest satellite-gauge precipitation products and their hydrologic applications over the Huaihe River basin. J. Hydrol., 536, 302-319, https://doi.org/10.1016/j.jhydrol.2016.02.054.

Sun, X.-L., Q. Yang, H.-L. Wang, and Y.-J. Wu, 2019: Can regression determination, nugget-to-sill ratio and sampling spacing determine relative performance of regression kriging over ordinary kriging? Catena, 181, 104092, https://doi.org/ 10.1016/j.catena.2019.104092.

Tang, G., Y. Ma, D. Long, L. Zhong, and Y. Hong, 2016: Evaluation of GPM Day-1 IMERG and TMPA Version-7 legacy products over Mainland China at multiple spatiotemporal scales. J. Hydrol., 533, 152-167, https://doi.org/10.1016/ j.jhydrol.2015.12.008.

Tapiador, F. J., and Coauthors, 2012: Global precipitation measurement: Methods, datasets and applications. Atmos. Res., 104-105, 70-97, https://doi.org/10.1016/j.atmosres.2011.10.021. , and Coauthors, 2017: Global precipitation measurements for validating climate models. Atmos. Res., 197, 1-20, https:// doi.org/10.1016/j.atmosres.2017.06.021.

Tong, K., F. Su, D. Yang, and Z. Hao, 2014: Evaluation of satellite precipitation retrievals and their potential utilities in hydrologic modeling over the Tibetan Plateau. J. Hydrol., 519, 423437, https://doi.org/10.1016/j.jhydrol.2014.07.044.

Villarini, G., and W. F. Krajewski, 2010: Review of the different sources of uncertainty in single polarization radar-based estimates of rainfall. Surv. Geophys., 31, 107-129, https://doi.org/ 10.1007/s10712-009-9079-x.

Ward, E., W. Buytaert, L. Peaver, and H. Wheater, 2011: Evaluation of precipitation products over complex mountainous terrain: A water resources perspective. Adv. Water Resour., 34, 1222-1231, https://doi.org/10.1016/j.advwatres.2011.05.007.

Wu, H., X. Zhang, S. Liang, H. Yang, and G. Zhou, 2012: Estimation of clear-sky land surface longwave radiation from MODIS data products by merging multiple models. J. Geophys. Res., 117, D22107, https://doi.org/10.1029/2012JD017567.

Yan, J., and M. Gebremichael, 2009: Estimating actual rainfall from satellite rainfall products. Atmos. Res., 92, 481-488, https://doi.org/10.1016/j.atmosres.2009.02.004.

Yong, B., L. Ren, Y. Hong, and J. Gourley, 2011: Evolving TRMMbased multi-satellite real-time precipitation estimation methods: Their impacts on hydrological prediction using the Variable Infiltration Capacity model in a high latitude basin. 2011 Fall Meeting, San Francisco, CA, Amer. Geophys. Union, Abstract H43C-1232.

Yu, M., X. Chen, L. Li, A. Bao, and M. J. De la Paix, 2011: Streamflow simulation by SWAT using different precipitation sources in large arid basins with scarce raingauges. Water Resour. Manage., 25, 2669-2681, https://doi.org/ 10.1007/s11269-011-9832-z.

Yu, Q., S. N. MacEachern, and M. Peruggia, 2011: Bayesian synthesis: Combining subjective analyses, with an application to ozone data. Ann. Appl. Stat., 5, 1678-1698, https:// doi.org/10.1214/10-AOAS444.

,-- , and -2013 : Clustered Bayesian model averaging. Bayesian Anal., 8, 883-908, https://doi.org/10.1214/13-BA859.

Yu, Z., H. Yu, P. Chen, C. Qian, and C. Yue, 2009: Verification of tropical cyclone-related satellite precipitation estimates in mainland China. J. Appl. Meteor. Climatol., 48, 2227-2241, https://doi.org/10.1175/2009JAMC2143.1. 